\title{
Article \\ The Impact of the COVID-19 Pandemic on Ambient Air Quality in China: A Quasi-Difference-in-Difference Approach
}

\author{
Tuo Zhang ${ }^{1}$ and Maogang Tang ${ }^{2, *}$ \\ 1 Graduate School of Economics, Kyoto University, Yoshidahonmachi, Sakyo Ward, Kyoto 606-8501, Japan; \\ ZhangTuoDr@hotmail.com \\ 2 School of Business, East China University of Science and Technology, 130 Meilong Road, \\ Shanghai 200237, China \\ * Correspondence: tangmaogang@126.com
}

check for updates

Citation: Zhang, T.; Tang, M. The Impact of the COVID-19 Pandemic on Ambient Air Quality in China: A Quasi-Difference-in-Difference Approach. Int. J. Environ. Res. Public Health 2021, 18, 3404. https:// doi.org/10.3390/ijerph18073404

Academic Editor: Benoit Nemery

Received: 18 February 2021

Accepted: 22 March 2021

Published: 25 March 2021

Publisher's Note: MDPI stays neutral with regard to jurisdictional claims in published maps and institutional affiliations.

Copyright: (C) 2021 by the authors Licensee MDPI, Basel, Switzerland. This article is an open access article distributed under the terms and conditions of the Creative Commons Attribution (CC BY) license (https:/ / creativecommons.org/licenses/by/ $4.0 /)$.

\begin{abstract}
The novel coronavirus (COVID-19) pandemic has provided a distinct opportunity to explore the mechanisms by which human activities affect air quality and pollution emissions. We conduct a quasi-difference-in-differences (DID) analysis of the impacts of lockdown measures on air pollution during the first wave of the COVID-19 pandemic in China. Our study covers 367 cities from the beginning of the lockdown on 23 January 2020 until April 22, two weeks after the lockdown in the epicenter was lifted. Static and dynamic analysis of the average treatment effects on the treated is conducted for the air quality index (AQI) and six criteria pollutants. The results indicate that, first, on average, the AQI decreased by about 7\%. However, it was still over the threshold set by the World Health Organization. Second, we detect heterogeneous changes in the level of different pollutants, which suggests heterogeneous impacts of the lockdown on human activities: carbon monoxide (CO) had the biggest drop, about $30 \%$, and nitrogen dioxide $\left(\mathrm{NO}_{2}\right)$ had the second-biggest drop, $20 \%$. In contrast, ozone $\left(\mathrm{O}_{3}\right)$ increased by $3.74 \%$ due to the changes in the $\mathrm{NO}_{\mathrm{x}} /$ VOCs caused by the decrease in $\mathrm{NO}_{\mathrm{x}}$, the decrease of $\mathrm{O}_{3}$ titration, and particulate matter concentration. Third, air pollution levels rebounded immediately after the number of infections dropped, which indicates a swift recovery of human activities. This study provides insights into the implementation of environmental policies in China and other developing countries.
\end{abstract}

Keywords: COVID-19; ambient air quality; air pollution emissions; quasi-difference-in-difference

JEL Classification: Q51; Q52; Q53

\section{Introduction}

At the end of 2019, an unusual coronavirus disease, eventually named COVID-19, was identified in Wuhan, China [1]. To curb its spread, the Chinese government enacted lockdown measures in the epicenter on 23 January 2020. The lockdown was expanded to the rest of the country soon after [2]. Non-essential businesses were closed, and residents were quarantined at home to cut off the viral transmission [3]. The drastic lockdown worked successfully [4,5], and it took 76 days for the epicenter to reopen.

These measures significantly reduced industrial, business, and residential activities [6]. One of the most concerning aspects is that energy consumption is reduced by the drastic lockdown measures and the cessation of human activities [7]. For instance, Wang, et al. [8] suggest that the fossil fuel-related $\mathrm{CO}_{2}$ emissions in China decreased by $18.7 \%$ YOY in the first quarter of 2020. Since ambient air quality is closely related to energy consumption, prior studies found that the air quality is improved dramatically during lockdown [9]. He, et al. [10] found that the operating vent numbers of NOx decreased by $24.68 \%$ in China during the lockdown period, which would reduce the NOx concentration by $9.54 \pm 6.00$.

The pandemic provided a distinct opportunity to examine the mechanisms and ways in which human activities affect air quality and pollution emissions. Moreover, in-depth 
research through a quasi-experiment of nature is worth conducting [11]. However, previous research has some limitations. First, most recent findings are based on descriptivecomparative methods, and the lack of proper identification strategies threatens the validity of their results; for instance, the direct comparison of air quality before and after lockdown overestimates its impacts, as seasonal trends are ignored. Second, most previous studies only cover a short period, which limits comprehensive interpretation not only on the shrinkage but also on the rebound effect [10]. In this case, the rebound effect is of more concern since it captures the economic recovery from the deadly shock of COVID-19. Third, the results of previous research are mostly static and lack a dynamic analysis.

Therefore, we adopt a quasi-difference-in-difference (quasi-DID) approach, which enables the comparison of air quality between the epidemical period in 2020 and Chinese New Year's leave in 2019, to estimate the net impact of the lockdown during the first peak of COVID-19. Moreover, through dynamic analysis, we identify the varying impact of the lockdown on air quality, which facilitates our understanding of human responses to the epidemic.

Our results suggest that, first, on average, the air quality index (AQI) decreased by about $7 \%$. Although our results indicate immense improvements, the air quality was still above the threshold set by the World Health Organization (WHO) and Chinese health standards. Second, we detect significant heterogeneous impacts on different pollutants. Carbon monoxide (CO) had the highest biggest drop, about $30 \%$, and nitrogen dioxide $\left(\mathrm{NO}_{2}\right)$ had the second-highest drop, about $20 \%$. In contrast, ozone $\left(\mathrm{O}_{3}\right)$ increased by $3.74 \%$ due to the changes in the $\mathrm{NO}_{x} /$ VOCs caused by the decrease in $\mathrm{NO}_{\mathrm{x}}$, the decrease of $\mathrm{O}_{3}$ titration, and the decrease of $\mathrm{PM}_{2.5}$ concentration. Third, although the AQI fell steeply after the lockdown, it increased immediately after the number of novel infections dropped, which indicates a swift economic recovery. Besides, we document preliminary cues of the rebound effect immediately after the lifting of lockdown measures in Wuhan.

This study's contribution to the literature is two-fold. First, compared with the recent studies in this field, our period covers the whole lockdown period, from the beginning of the lockdown on January 23 to two weeks after the lift of lockdown in Wuhan. Therefore, it enables us to not only identify the shrinkage but also study the rebound of air pollution and human activities, which is more relevant to current opening-up processes in most regions. To the best of our knowledge, this is the first study that identifies the dynamic impacts of lockdown measures on the environment. Second, this study also contributes to future environmental policy measures. Although the temporary shutdown of pollution-intensive plants has become a common practice during periods of extreme air pollution, the impact of such emergency measures is still unclear. Our research sheds light on the mechanisms of human activities affecting air quality and pollution emissions.

The remainder of this paper is organized as follows: Section 2 provides information on the data sources and empirical methodology. Section 3 presents the average effect of the lockdown on the air quality in China. Section 4 reports the dynamic patterns of the effects of the COVID-19 lockdown. Finally, Section 5 summarizes this study and discusses its limitations.

\section{Data and Empirical Methodology}

\subsection{Datasets}

In this study, we combine three datasets: hourly real-time reports of air pollutants, daily historical meteorological information, and pandemic data. All three datasets are at the prefecture and county levels and cover 367 cities in China.

Air quality data were collected from the China National Urban Air Quality Real-time Publishing Platform sponsored by the China National Environmental Monitoring Center. The platform reports the concentrations of six air pollutants- $\mathrm{SO}_{2}, \mathrm{NO}_{2}, \mathrm{CO}, \mathrm{O}_{3}, \mathrm{PM}_{10}$, and $\mathrm{PM}_{2.5}$ (in micrograms $[\mu \mathrm{g}]$ per cubic meter under standard conditions) - as well as the aggregate AQI based on the Chinese Technical Regulation on Ambient Air Quality Index. Its wide coverage facilitates our investigation of the lockdown's impact on different human 
activities. For example, $\mathrm{NO}_{2}$ is an effective way to track transportation in urban areas [12], while $\mathrm{SO}_{2}$ is mostly caused by flue gas of coal-fired boilers [13]. Notably, air quality monitoring stations are always located within urban areas, especially for prefecture-level cities [14]. Therefore, the pollution data largely represent air quality in the downtown areas of cities.

We collected prefectural infection data from a public GitHub repository and crosschecked the data against official daily reports by the National Health and Family Planning Commission. This dataset contains daily cumulative confirmed cases, cumulative death toll, and cumulative recovered cases for each infected city since 1 December 2019, when the first case was traced back to Wuhan.

Meteorological conditions also influence ambient air quality [15-17]. We took daily meteorological information from the website of the China Meteorological Data Service Center. Data reported by meteorological stations located in the city downtowns were chosen to match the collected air quality information. Thus, in our analysis, we could control for meteorological conditions, including temperature [18], precipitation [19], and wind [20], which affect air pollutants transmissions.

\subsection{Quasi-DID Identification}

\subsubsection{Identification Strategy}

Previous studies have used various events to explore exogenous shocks on air quality. For example, Chiquetto, et al. [21] studied the impact of a sudden truck driver strike in Sao Paulo on urban air pollution. Li, et al. [22] took the suspended production of heavypolluting factories during the 2008 Beijing Summer Olympics as an environmental event to study its impact on outpatient visits for asthma owing to the improvement of air quality. Additionally, Feng, et al. [23] conducted an event study on the environmental impact of the Chinese Spring Festival. In this vein, we build a quasi-DID model to identify the causal relationship between air pollution and the lockdown imposed under the COVID-19 state of emergency in China. As illustrated in Figure 1, if the influence of meteorological conditions is not considered, there is a clear reversal in air quality during the Chinese New Year holiday $[23,24]$. As the new year approaches, factories shut down and release their workers so they can travel home and spend time with their families during the Spring Festival (which was 24-30 January 2020) [25]. Besides, most industrial plants remain closed until the end of the holiday [26].

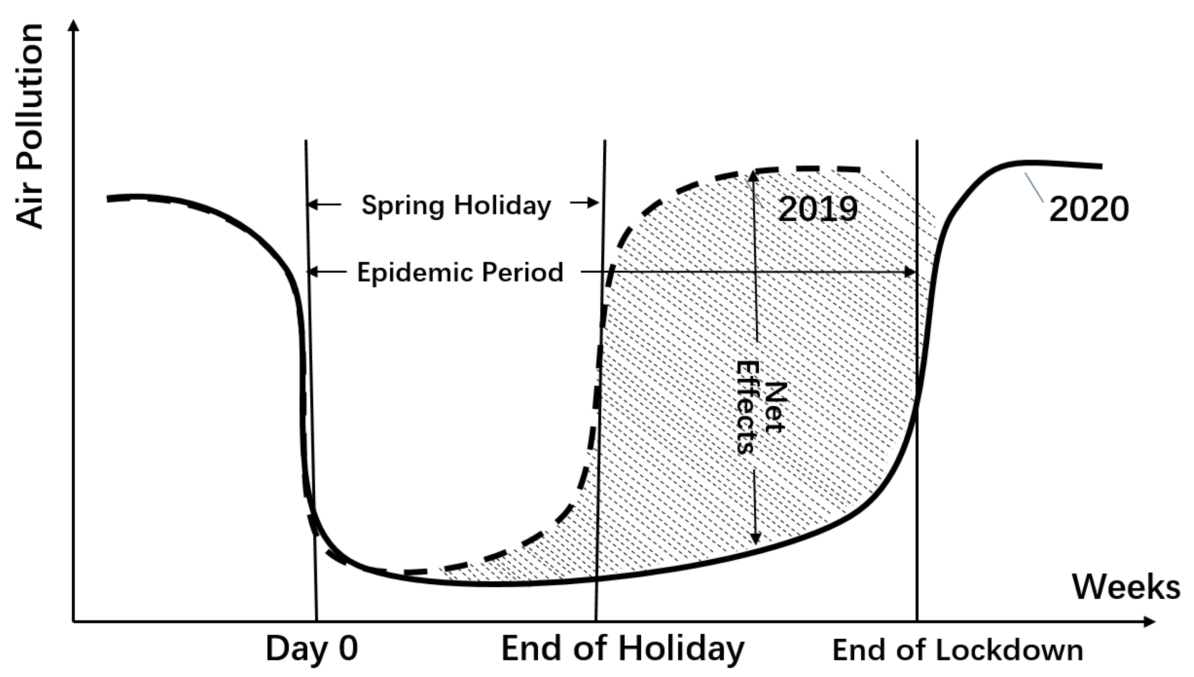

Figure 1. Illustration of an identification strategy. Note: This figure illustrates the quasi-DID approach in this study. Day zero in 2019 is set as the beginning of Chinese New Year's leave, February 5, while day zero in 2020 is set as the beginning of the lockdown period for most Hubei cities, January 23. We choose 22 April 2020, as the end of our research period in 2020, two weeks after Wuhan lifted its lockdown and resumed transportation conditionally on April 8. 
The lockdown measures induced by the COVID-19 pandemic have functioned similarly to the usual New Year holiday period [27]. Residents are required to stay at home and are only allowed to visit nearby grocery stores. Most factories are temporarily shut down [4]. Therefore, non-essential industrial activities are restricted. Highways, as well as major carriageways, are completely blocked. Only vehicles with special permissions can travel across jurisdictions [28].

Therefore, it is feasible to compare the air quality between the 2020 lockdown period and the 2019 Chinese New Year's holiday to estimate the net impact of the COVID-19 lockdown. Day zero in 2019 is set as the beginning of Chinese New Year's leave, February 5 , while day zero in 2020 is set as the beginning of the lockdown period for most Hubei cities, January 23. We choose April 22 as the end of our research period, two weeks after Wuhan lifted its lockdown and resumed transportation conditionally on April 8.

As shown in Figure 1, we can calculate the daily impact, which is given by the concentration of air pollutants in 2019 minus that in 2020. We can also identify the dynamic impacts day by day. Besides, the shaded area, as the integral of impact over time, represents the aggregated impact of the COVID-19 lockdown on air quality. Compared to the single difference model used in other studies, such as Li, et al. [29], our DID approach can eliminate the impact of the New Year holiday; hence, it is more accurate in estimating the average treatment effects on the treated.

\subsubsection{The Average Effect on Air Pollution}

Based on the above analysis, we evaluate the treatment impact of the lockdown on air pollution with the following DID regression equation:

$$
y_{i t}=\gamma \text { Treat }_{i} \times \text { Post }_{t}+\beta_{1} \text { Treat }_{i}+\beta_{2} \text { Post }_{t}+\Gamma X_{i t}+\eta_{i}+\delta_{t}+\varepsilon_{i t}
$$

where the dependent variable $y_{i t}$ is the proxy for air quality. The dummy variable Treat takes " 1 " for observations in 2020 and " 0 " for those in 2019 . The dummy variable Post takes " 1 " for periods after January 23 in 2020 and " 1 " after February 5 in 2019. The term $\eta_{i}$ captures the prefectural fixed effects, $\delta_{t}$ is the time fixed effects, and $\varepsilon_{i t}$ is the random error term.

Besides, we control for a full set of daily meteorological variates $X_{i t}$ in Equation (1) following previous research $[30,31]$. $X_{i t}$ contains the highest and lowest temperatures, the Beaufort scale of predominant winds in $24 \mathrm{~h}$, and a dummy for rainy days.

The coefficient obtained by the first difference before and after the 2020 lockdown is $\gamma+\beta_{2}$. The coefficient obtained by the first difference before and after the 2019 Spring Festival is $\beta_{2}$. We differentiate the two distinct results again, so $\gamma$ captures the net effect of the lockdown measures after the COVID-19 outbreak.

\subsubsection{Dynamic Impacts on Air Pollution}

We investigate the dynamic evolution of the impacts on air pollution by using the following equation:

$$
y_{i t}=\sum_{t=1}^{n} \gamma_{t} \text { Treat }_{i} \times \text { Post }_{t}+\beta_{1} \text { Treat }_{i}+\beta_{2} \text { Post }_{t}+\Gamma X_{i t}+\eta_{i}+\varepsilon_{i t}
$$

where Post is the dummy variable for a specific period after day zero. In our analysis framework, Post $t$ is defined as the $t^{\text {th }}$ week after the beginning of the lockdown. Therefore, the coefficient $\gamma_{t}$ captures the net effects during its corresponding week $t$.

\subsection{Summary Statistics}

We report the summary statistics of the urban ambient AQI for the two periods in Table 1. The observations in the control and treatment groups are divided into pre-periods before the event day and post-periods after the event day. 
Table 1. Summary Statistics of the Urban Ambient Air Quality Index (AQI).

\begin{tabular}{|c|c|c|c|c|c|c|c|}
\hline \multicolumn{8}{|c|}{ Panel A: 2019 Sample } \\
\hline & $(1)$ & $(2)$ & (3) & (4) & (5) & (6) & (7) \\
\hline & Obs. & Mean & p10 & p25 & p50 & p75 & p90 \\
\hline All & 45718 & 77.32 & 36.33 & 47.58 & 64.21 & 89.63 & 134.85 \\
\hline pre: $[-22,-1]$ & 7944 & 92.40 & 41.46 & 55.75 & 78.94 & 113.88 & 158.82 \\
\hline post: $[0,93]$ & 33444 & 71.55 & 35.92 & 46.46 & 61.08 & 81.42 & 116.79 \\
\hline \multicolumn{8}{|c|}{ Panel B: 2020 Sample } \\
\hline & $(1)$ & $(2)$ & (3) & $(4)$ & (5) & (6) & (7) \\
\hline & Obs. & Mean & p10 & p25 & p50 & p75 & p90 \\
\hline All & 41960 & 67.86 & 27.96 & 39.21 & 56.58 & 79.05 & 116.71 \\
\hline pre: $[-22,-1]$ & 7955 & 90.25 & 31.90 & 46.96 & 72.71 & 116.94 & 179.36 \\
\hline post: $[0,93]$ & 33644 & 62.32 & 27.38 & 37.92 & 54.25 & 73.46 & 99.28 \\
\hline \multicolumn{8}{|c|}{ Panel C: Mean difference of city-level air pollutants } \\
\hline & (1) & $(2)$ & (3) & & (1) & $(2)$ & (3) \\
\hline & pre:2019 & post:2019 & post- & 019 & pre: 2020 & post:2020 & post-pre:2020 \\
\hline AQI & 92.40 & 71.55 & $-20.85 * * *$ & & 90.25 & 62.32 & $-27.92 * * *$ \\
\hline \multicolumn{8}{|l|}{ Type: } \\
\hline $\mathrm{SO}_{2}$ & 16.42 & 11.42 & $-5.00 * * *$ & & 14.21 & 10.48 & $-3.73^{* * *}$ \\
\hline $\mathrm{NO}_{2}$ & 36.36 & 26.56 & $-9.80 * * *$ & & 37.24 & 22.21 & $-15.03 * * *$ \\
\hline $\mathrm{CO}$ & 1.15 & 0.80 & $-0.34^{* * *}$ & & 1.15 & 0.74 & $-0.41^{* * *}$ \\
\hline $\mathrm{O}_{3}$ & 75.31 & 103.77 & $28.46^{* * *}$ & & 69.24 & 100.84 & $31.6^{* * *}$ \\
\hline $\mathrm{PM}_{2.5}$ & 63.43 & 41.97 & $-21.45^{* * *}$ & & 65.18 & 38.52 & $-26.66^{* * *}$ \\
\hline $\mathrm{PM}_{10}$ & 99.53 & 76.79 & $-22.73^{* * *}$ & & 86.60 & 66.58 & $-20.02^{* * *}$ \\
\hline
\end{tabular}

Note: The summary statistics are calculated for the daily AQI of all cities in the sample. The unit for CO is mg per cubic meter, and the unit for other pollutants is $\mu \mathrm{g}$ per cubic meter, both under standard conditions. Day zero is January 23 for 2020 (the date when the Wuhan lockdown was implemented), while day zero for 2019 is February 5 . The pre-period is defined as $[-22,-1]$, while the post-period is defined as $[0,93]$, according to day zero. ${ }^{* * *} p<0.01,{ }^{* *} p<0.05,{ }^{*} p<0.1$.

Panel A reports the summary statistics for the control group in 2019. The average AQI for the whole period, pre-period, and post-period are 77.32, 92.40, and 71.55, respectively. Compared to the pre-period, the average AQI decreased by 20.85 , or $22.56 \%$. We find a similar pattern in the change in the median. The medians of the three periods are 64.21 , 78.94 , and 61.08 , respectively. Moreover, we find a sharp decrease of 17.86 , or $22.62 \%$, in the median of the AQI. The decrease is likely attributed to two factors: the seasonal change caused by meteorological conditions and socioeconomic factors such as the spring festival.

Panel B reports the summary statistics of the control group in 2020. The decrease recurs in that year. For example, the average AQI for the whole period, pre-period, and post-period are $67.86,90.25$, and 62.32 , respectively. Compared with the pre-period, the average AQI decreased by 27.93 , or $30.95 \%$. The medians of the three periods are 56.58 , 72.71 , and 54.25 , respectively. Besides, we find a sharp decrease of 18.45 or $25.37 \%$ in the median of the AQI. The decrease is likely attributed to two factors: the seasonal change caused by meteorological conditions and socio-economic factors such as the lockdown measures induced by the COVID-19 pandemic.

As for the quasi-DID design, we can roughly estimate the impacts of the COVID-19 lockdown on the AQI by subtracting the AQI decrease in 2020 from the decrease in 2019. For instance, the average treatment effect is roughly 7.07 for the AQI if meteorological conditions stay the same in both years. Although the decline is significant, the AQI is still above the healthy level recommended by the WHO (World Health Organization (2 May 2018), Ambient (outdoor) air pollution, from https://www.who.int/news-room/ fact-sheets/detail/ambient-(outdoor)-air-quality-and-health (accessed on 11 March 2021), and outdoor air quality is still unhealthy according to environmental non-government organizations [32]. 
Column (1) of Panel C reports the comparisons of the group mean and the t-test results for the AQI. We can see that in the single difference design, the AQI decreases significantly in both years. However, the gap grew by 7.07 in 2020, which is 33.90\% less than in 2019 .

We also report comparisons of all types of air pollutants to obtain an integrated overview of the impacts. Five out of the six pollutants significantly decreased after the event day, except for $\mathrm{O}_{3}$. Fine atmospheric particulate matter $\mathrm{PM}_{2.5}$ and $\mathrm{PM}_{10}$ experienced the greatest drop. The levels of primary pollutants $\mathrm{SO}_{2}, \mathrm{NO}_{2}$, and $\mathrm{CO}$ also declined, confirmed by the pollution monitoring satellites of the National Aeronautics and Space Administration and the European Space Agency. The increase of $\mathrm{O}_{3}$ can mainly be attributed to the seasonal change of ultraviolet (UV) rays in solar radiation, which is a photo catalyst for the generation of $\mathrm{O}_{3}$ particles. Panel $\mathrm{C}$ also shows that the primary air pollutant during the COVID-19 pandemic is $\mathrm{PM}_{2.5}$, whose levels are nearly twice as high as the annual limits recommended by the $\mathrm{WHO}$. Other pollutants, such as $\mathrm{NO}_{2}$ and $\mathrm{SO}_{2}$, are well below their healthy levels.

We illustrate the time-varying patterns of the AQI and $\mathrm{NO}_{2}$ levels for regions of varying epidemic severity in Figures 2 and 3, respectively. To show the impact of the COVID-19 lockdown on air pollution, the total sample is classified into four groups based on their epidemic severity, from highest severity to lowest: Wuhan city, cities inside Hubei Province, cities outside Hubei Province, and the full sample. The patterns for the AQI and $\mathrm{NO}_{2}$ levels are quite similar except that the changes in $\mathrm{NO}_{2}$ levels are typical. In the epicenter, Wuhan, we see a steep drop immediately after the lockdown. The pollution level stayed at its background concentration rate for nearly 12 weeks. The background concentration rate can be used to track fundamental human activities that were not affected by lockdown measures, for example, the transportation of daily necessities. Moreover, after the lockdown was lifted, the concentration gradually increased and returned to its normal level, just as it was in 2019. The pattern of pollution experienced in the cities in Hubei Province is similar to that in Wuhan. However, for the average city in China, the concentration of pollutants bounced back to normal levels around seven weeks after the event day, which is much quicker than in the epicenter. Figure 4 depicts the time-varying patterns of $\mathrm{SO}_{2}$, which shows that $\mathrm{SO}_{2}$ emissions instead increased when the lockdown was implemented. This $\mathrm{SO}_{2}$ emissions trend echoes that of 2019, but after about three weeks from the date of lockdown implementation, $\mathrm{SO}_{2}$ emissions were slightly lower than those in the same period in 2019. After economic activities resumed, $\mathrm{SO}_{2}$ emissions were higher than those in the same period in 2019 due to increased industrial production.

The parallel trend assumption is essential for the counterfactual setting in the DID approach [33]. All these figures show roughly similar trends of air quality change before the event day, which validates the parallel trend assumption. 

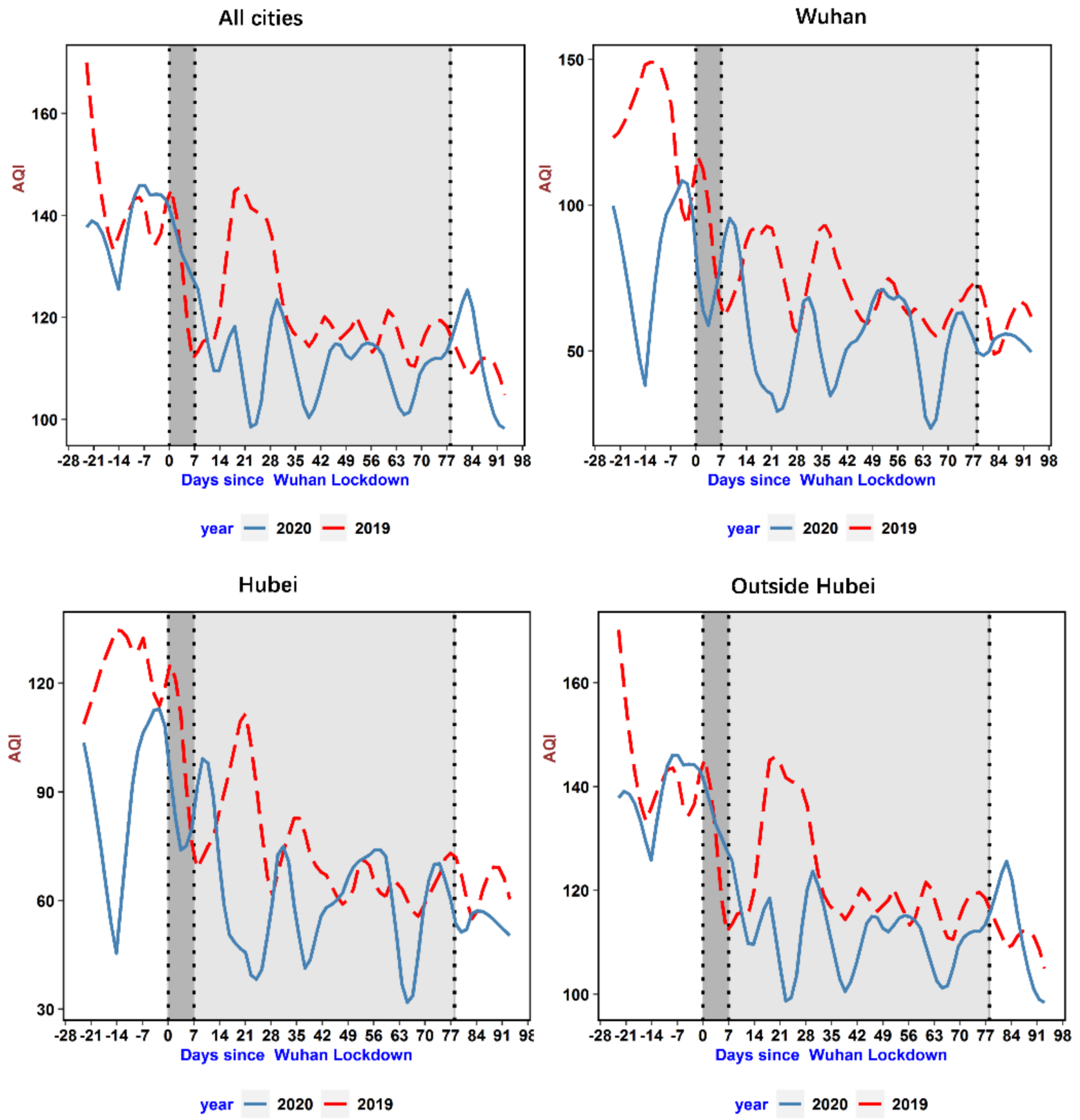

Figure 2. The time-varying patterns of the Air Quality Index (AQI) for different regions. Note: The daily average AQI is the average of the hourly AQI during the day. AQI is a simple, unitless index for reporting air quality and indicates the quality of the air and its health effects. Our sample covers 367 prefecture and county-level cities in China. The sample period for 2019 is from 14 January 2019to 9 May 2019, and the sample period for 2020 is from 1 January 2020 to 22 April 2020. The event day of 2020 is defined as January 23 (the date when the Wuhan lockdown was enacted), while the event day of 2019 is defined as February 5, one day before the Chinese New Year's Eve. The red line shows the AQI variation for the sample period in 2020, while the blue line displays that for 2019. The 2019 Spring Festival is shown in dark grey, and the 2020 lockdown period is in light grey. 


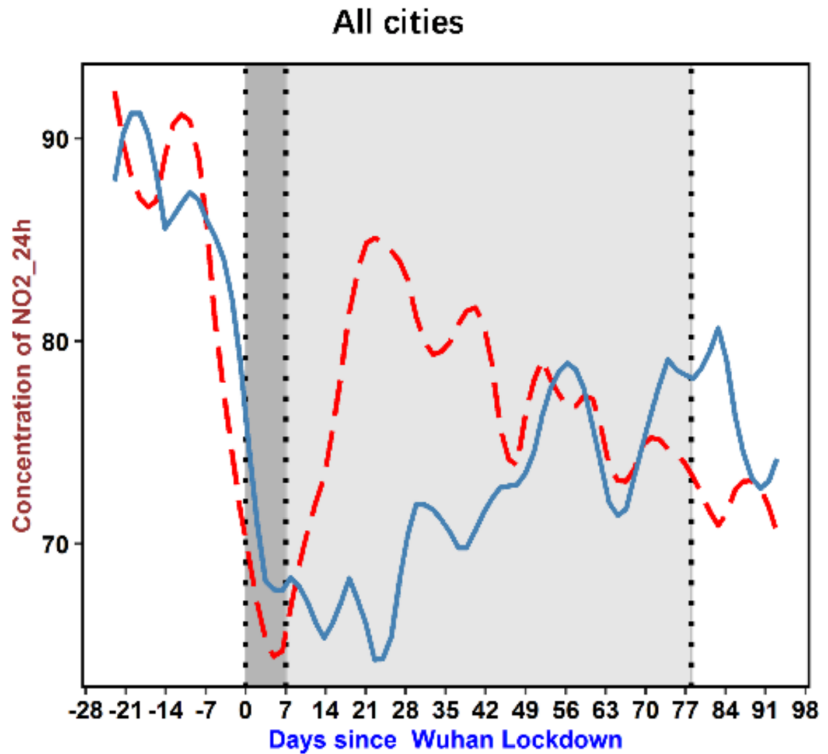

year $-2020-2019$

Hubei

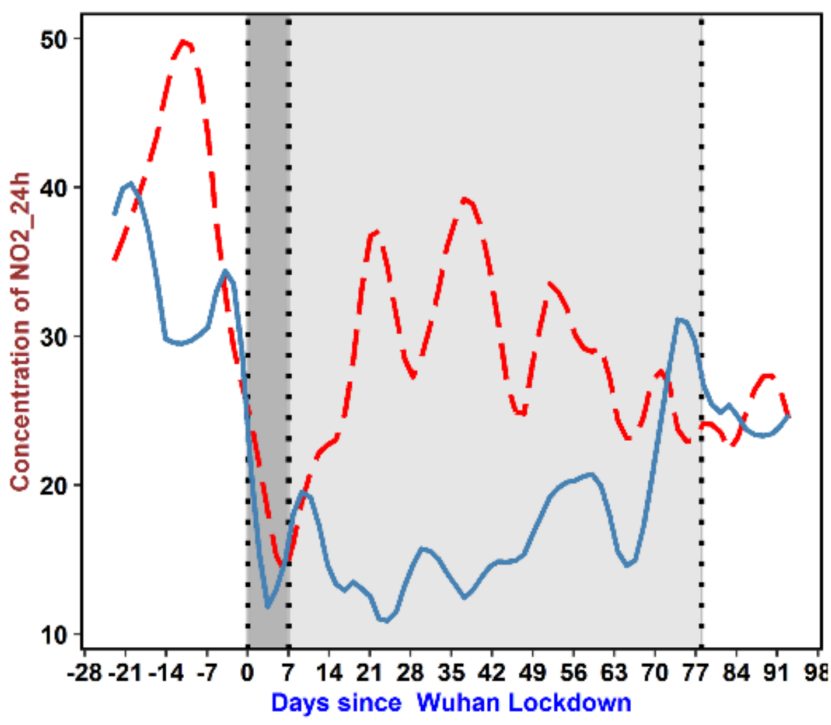

year $-2020-2019$
Wuhan

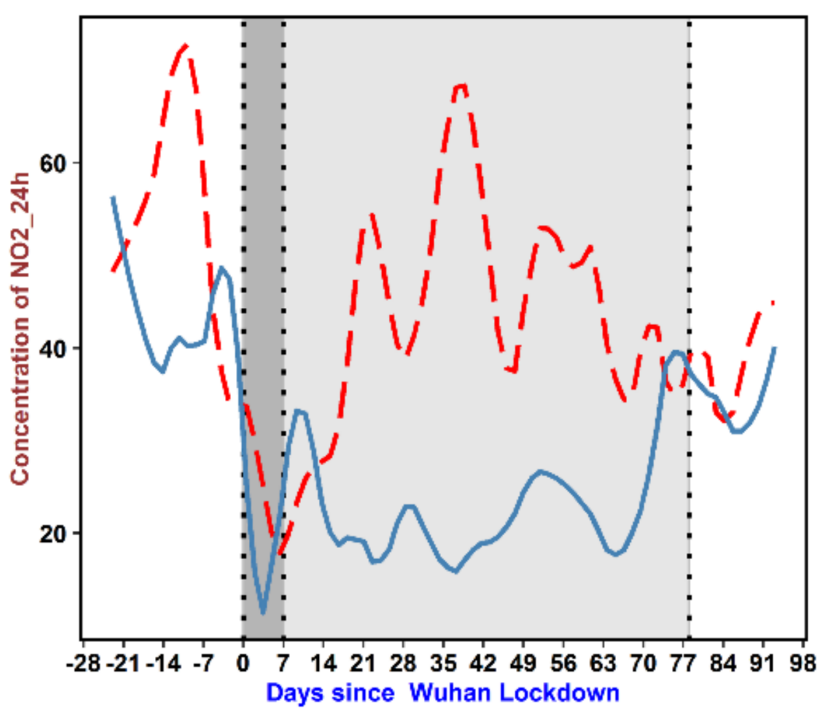

year $-2020-2019$

Outside Hubei

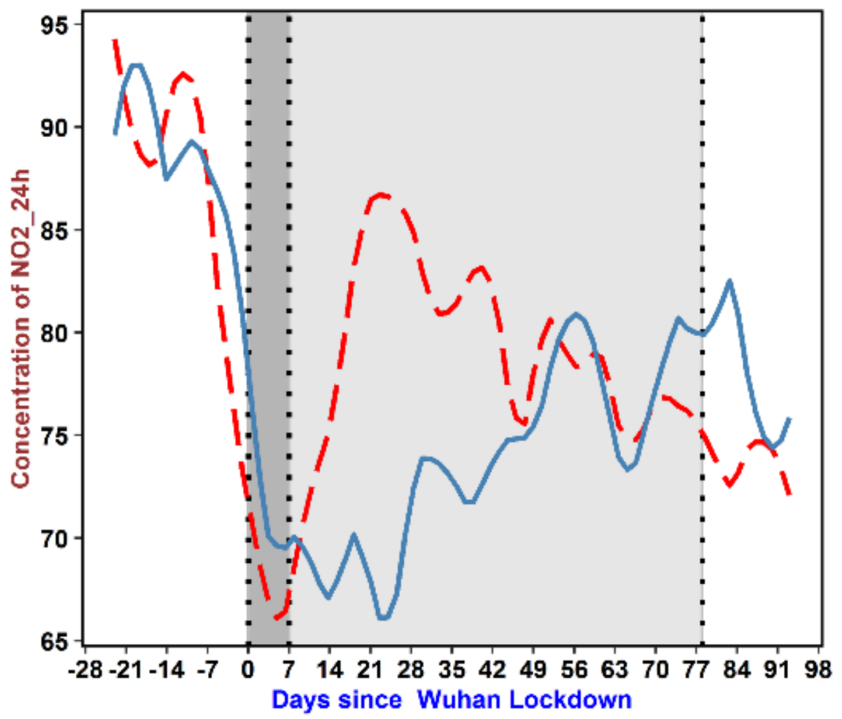

year $-2020-2019$

Figure 3. The time-varying patterns of $\mathrm{NO}_{2}$ for different regions. Note: The daily average of $\mathrm{NO}_{2}$ is the average of hourly $\mathrm{NO}_{2}$ levels during the day. The figure elements are the same as in Figure 2. 


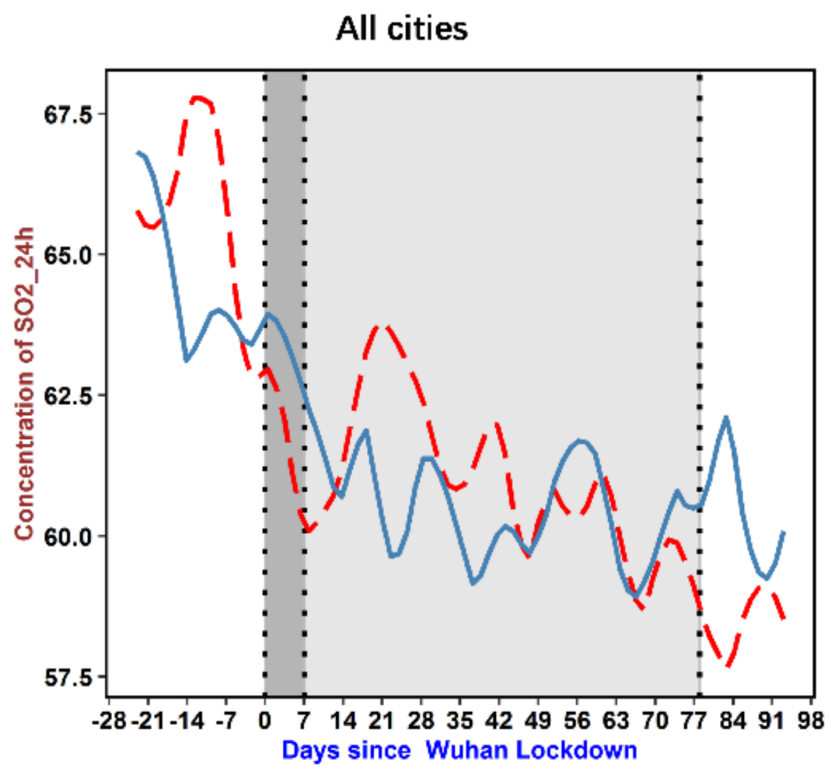

year $-2020-2019$

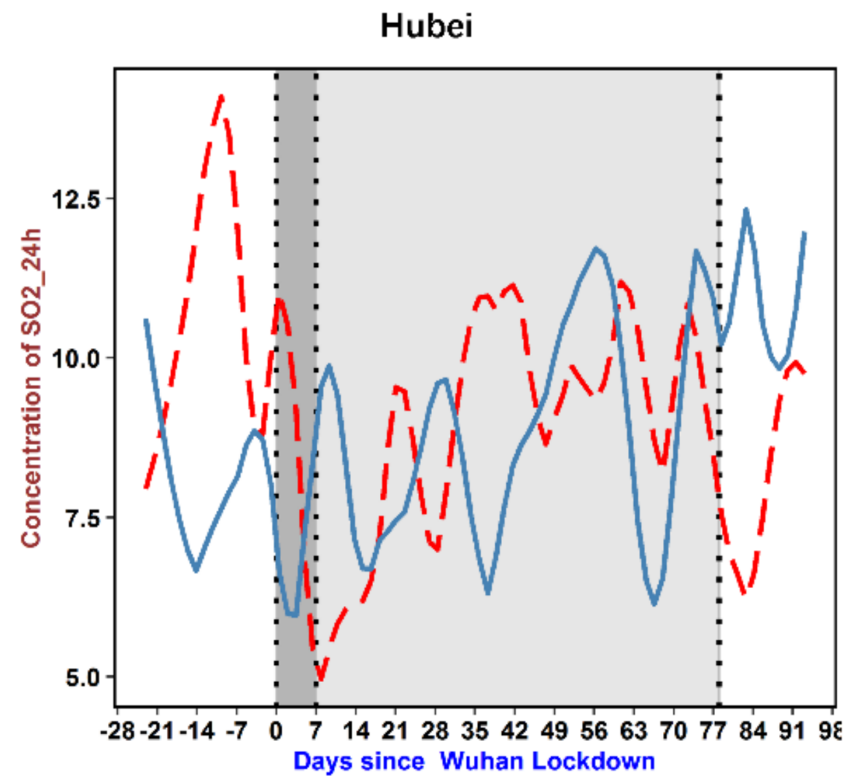

year $-2020-2019$
Wuhan

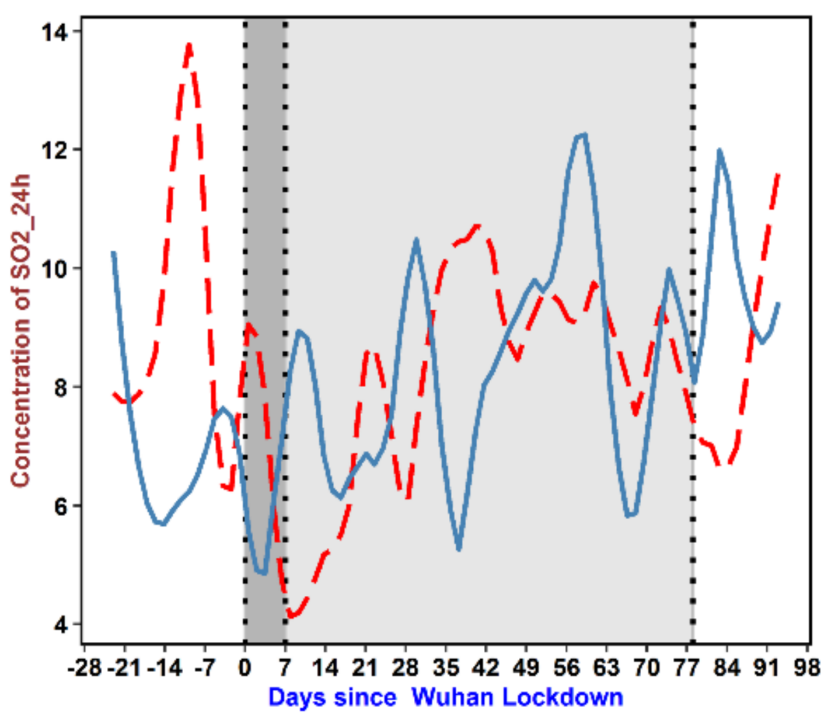

year $-2020-2019$

\section{Outside Hubei}

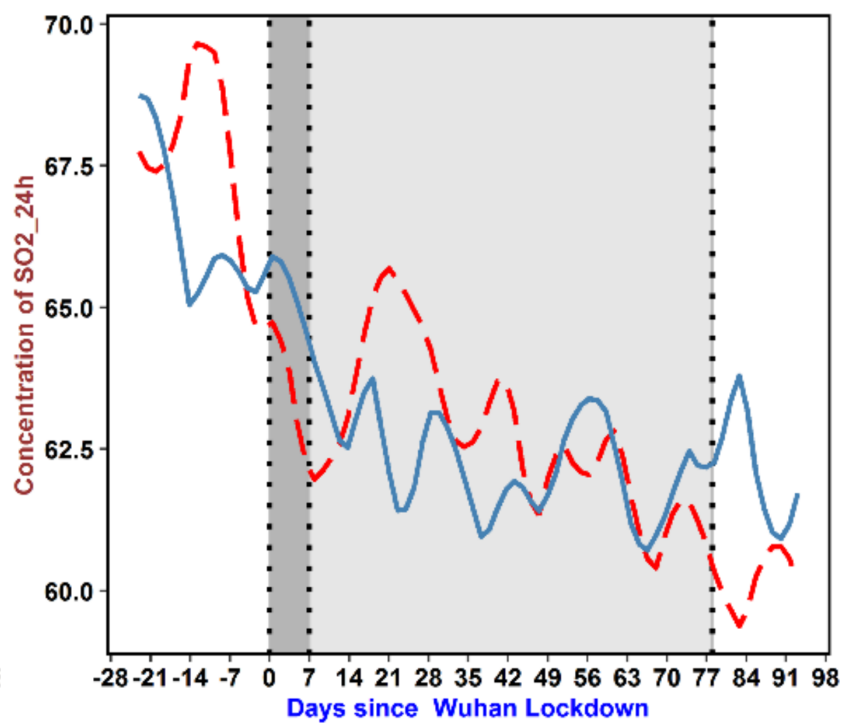

year $-2020-2019$

Figure 4. The time-varying patterns of $\mathrm{SO}_{2}$ for different regions. Note: The average daily $\mathrm{SO}_{2}$ is the average of hourly $\mathrm{SO}_{2}$ levels during the day. The figure elements are the same as in Figure 2.

\section{The Average Effect on Air Quality}

We begin by estimating the average effect of the COVID-19 lockdown on the daily AQI, and we estimate the results of Equation (1) with the AQI as the dependent variable. Alternative sets of control variates are reported in Table 2. Column (1) reports a model with no control on meteorological variates. The average net impact of the COVID-19 lockdown on the AQI is -7.125 . This result is similar to our estimates in Table 1 . 
Table 2. The impact of the COVID-19 lockdown on ambient air quality.

\begin{tabular}{|c|c|c|c|c|c|}
\hline \multirow{2}{*}{ Dependent Variable } & \multicolumn{5}{|c|}{ AQI } \\
\hline & (1) & (2) & (3) & (4) & (5) \\
\hline Treat*Post & $\begin{array}{c}-7.125^{* * *} \\
(1.605)\end{array}$ & $\begin{array}{c}-5.604^{* * * *} \\
(1.842)\end{array}$ & $\begin{array}{c}-4.749 * * \\
(1.945)\end{array}$ & $\begin{array}{c}-5.831^{* * *} \\
(1.827)\end{array}$ & $\begin{array}{c}-4.884 \text { ** } \\
(1.944)\end{array}$ \\
\hline Treat & $\begin{array}{l}-1.412 \\
(1.452)\end{array}$ & $\begin{array}{c}-4.176^{* * *} \\
(1.598)\end{array}$ & $\begin{array}{c}-4.226^{* * *} \\
(1.596)\end{array}$ & $\begin{array}{c}-4.034^{* *} \\
(1.588)\end{array}$ & $\begin{array}{c}-4.172 * * * \\
(1.602)\end{array}$ \\
\hline Wind Speed & & $\begin{array}{c}-0.424 \\
(0.296)\end{array}$ & $\begin{array}{c}-0.559 * \\
(0.292)\end{array}$ & $\begin{array}{c}-0.372 \\
(0.296)\end{array}$ & $\begin{array}{l}-0.478 \\
(0.293)\end{array}$ \\
\hline L.Wind Speed & & $\begin{array}{c}-6.094^{* * *} \\
(0.461)\end{array}$ & $\begin{array}{c}-6.033^{* * *} \\
(0.462)\end{array}$ & $\begin{array}{c}-6.088^{* * *} \\
(0.460)\end{array}$ & $\begin{array}{c}-6.072 * * * \\
(0.459)\end{array}$ \\
\hline L2. Wind Speed & & $\begin{array}{c}-5.146^{* * *} \\
(0.311)\end{array}$ & $\begin{array}{c}-5.172 * * * \\
(0.309)\end{array}$ & $\begin{array}{c}-5.151^{* * *} \\
(0.311)\end{array}$ & $\begin{array}{c}-5.163 * * * \\
(0.307)\end{array}$ \\
\hline L3. Wind Speed & & $\begin{array}{c}-2.759 * * * \\
(0.286)\end{array}$ & $\begin{array}{c}-2.799^{* * * *} \\
(0.280)\end{array}$ & $\begin{array}{c}-2.763^{* * *} \\
(0.286)\end{array}$ & $\begin{array}{c}-2.865^{* * *} \\
(0.283)\end{array}$ \\
\hline L4. Wind Speed & & $\begin{array}{c}-2.037^{* * *} \\
(0.314)\end{array}$ & $\begin{array}{c}-2.199 * * * \\
(0.294)\end{array}$ & $\begin{array}{c}-2.054^{* * *} \\
(0.314)\end{array}$ & $\begin{array}{c}-2.219^{* * *} \\
(0.293)\end{array}$ \\
\hline Temperature (Minimum) & & & $\begin{array}{c}0.093 \\
(0.098)\end{array}$ & & $\begin{array}{c}0.120 \\
(0.110)\end{array}$ \\
\hline Temperature (Highest) & & & $\begin{array}{c}0.385 \text { ** } \\
(0.166)\end{array}$ & & $\begin{array}{c}0.396^{* *} \\
(0.178)\end{array}$ \\
\hline Sunny & & & & $\begin{array}{c}1.189^{* * *} \\
(0.433)\end{array}$ & $\begin{array}{c}1.296^{* * *} \\
(0.487)\end{array}$ \\
\hline Constant & $\begin{array}{c}100.713^{* * *} \\
(1.937)\end{array}$ & $\begin{array}{c}112.625^{* * *} \\
(3.152)\end{array}$ & $\begin{array}{c}112.971 \text { *** } \\
(3.078)\end{array}$ & $\begin{array}{c}111.668^{* * *} \\
(3.173)\end{array}$ & $\begin{array}{c}117.206^{* * *} \\
(4.102)\end{array}$ \\
\hline Date Dummy & $\mathrm{Y}$ & $\mathrm{Y}$ & $\mathrm{Y}$ & $\mathrm{Y}$ & $\mathrm{Y}$ \\
\hline City Dummy & $\mathrm{Y}$ & $\mathrm{Y}$ & $\mathrm{Y}$ & $\mathrm{Y}$ & $\mathrm{Y}$ \\
\hline Groups & 367 & 335 & 335 & 335 & 335 \\
\hline Sample & 83,710 & 71,597 & 71,597 & 71,597 & 71,597 \\
\hline adj R2 & 0.127 & 0.141 & 0.143 & 0.141 & 0.144 \\
\hline
\end{tabular}

Note: This table reports the regression results of the average impact of the COVID-19 lockdown on the Air Quality Index (AQI) of all cities in the sample. The dependent variable is the AQI of each city. The dummy variable "treat" is defined as 1 for observations in 2020, and 0 otherwise. "Post" is defined as 1 for the post periods [0,58], and 0 otherwise. The event day is defined as January 23 for 2020 (the date on which the Wuhan lockdown was implemented), while the event day for 2019 is defined as February 5. Standard errors reported in parentheses are clustered at the city level. ${ }^{* * *} p<0.01,{ }^{* *} p<0.05,{ }^{*} p<0.1$.

Unfavorable weather conditions lead to an increase in the level of air pollutants, even when emissions remain unchanged [34,35]. For example, high wind speeds lead to more dispersion of particulates [36]. Furthermore, the effect of wind speed on air quality is continuous, and a given day's wind speed may affect air quality for several days. Therefore, in Column (2), we control the Beaufort scale of predominant winds in the current day and the past four days. In previous studies, only the wind on a particular day was analyzed $[30,31]$. We find that the wind scale of a particular day has little impact because the diffusion of pollutants takes time. The lag terms are influential. Although the impacts of the wind scale fade as time passes, the wind will exert its impact even after four days. After controlling for the wind condition, the effect declines to -5.604 .

In addition to wind speed, temperature and humidity also impact air quality. High temperatures can increase oxidation and production of sulfate but reduce nitrate levels through higher volatilization of particles to gas [37]. In Columns (3) and (4), we control for the temperature and rain dummy, respectively. Besides, in Column (5), we control for a full set of meteorological conditions. The ATT is smaller compared to that in Column (1), but it is still significant. The results indicate that the net impact of the COVID-19 lockdown on the AQI is -4.884 , or $-7.84 \%$ compared to what it was in 2019 . Hence, our study suggests that news reports and former studies may exaggerate the COVID-19 lockdown's impact on air pollution by failing to consider meteorological conditions. Our results support the findings of Wang, et al. [38] that severe air pollution is associated with both anthropogenic activities and meteorological conditions. 
Notably, the AQI reduction in our results is only half of that estimated in He, Pan, and Tanaka [3]. The major reason for this is that they focused on the AQI in the first-month post-lockdown, while our study covers the full period from the lockdown's beginning to two weeks after Wuhan's reopening. Since their results are based on the first half of the lockdown period in which the most stringent quarantine measures were implemented, their results would overestimate impacts on air pollution.

Ambient air pollution exposure has been found to correlate with respiratory $[39,40]$ and cardiovascular [41,42] diseases, and lead to increased non-trauma deaths [43-45]. It has been reported that severe air pollution in China contributes to about 1.6 million premature deaths per year [46]. Pollution control measures can effectively reduce premature deaths effectively even when implemented in a short period [45]. Thus, we project that the decrease of air pollutants reduced the premature deaths by 150,000 nationwide during the research period, according to the all-cause death rate estimated by Dutheil, Baker, and Navel [9]. This number far exceeds the officially reported deaths due to COVID-19.

The overall analysis confirms that the AQI level declined moderately due to the outbreak of COVID-19. However, one may wonder which pollutant level had the most drastic change. Table 3 reports the estimated results of each pollutant. Columns (1)-(6) report the results for $\mathrm{SO}_{2}, \mathrm{NO}_{2}, \mathrm{CO}, \mathrm{O}_{3}, \mathrm{PM}_{2.5}$, and $\mathrm{PM}_{10}$, respectively. The estimation results show diversified impacts of the lockdown measures on different air pollutants, as follows.

Table 3. The impact of the COVID-19 lockdown on different air pollutants.

\begin{tabular}{|c|c|c|c|c|c|c|}
\hline & (1) & (2) & (3) & (4) & (5) & (6) \\
\hline & $\begin{array}{c}\mathrm{SO}_{2} \\
\text { Concentration }\end{array}$ & $\begin{array}{c}\mathrm{NO}_{2} \\
\text { Concentration }\end{array}$ & $\begin{array}{c}\mathrm{CO} \\
\text { Concentration }\end{array}$ & $\begin{array}{c}\mathrm{O}_{3} \\
\text { Concentration }\end{array}$ & $\begin{array}{c}\qquad \mathrm{PM}_{2.5} \\
\text { Concentration }\end{array}$ & $\begin{array}{c}\mathrm{PM}_{10} \\
\text { Concentration }\end{array}$ \\
\hline Treat*Post & $\begin{array}{c}1.679^{* * *} \\
(0.343)\end{array}$ & $\begin{array}{c}-5.113 * * * \\
(0.402)\end{array}$ & $\begin{array}{c}-0.105^{* * *} \\
(0.012)\end{array}$ & $\begin{array}{c}3.881^{* * *} \\
(0.794)\end{array}$ & $\begin{array}{c}-5.772 * * * \\
(1.526)\end{array}$ & $\begin{array}{c}2.721 \\
(2.198)\end{array}$ \\
\hline Treat & $\begin{array}{c}-3.073^{* * *} \\
(0.425)\end{array}$ & $\begin{array}{l}-0.156 \\
(0.427)\end{array}$ & $\begin{array}{c}0.019 \\
(0.013)\end{array}$ & $\begin{array}{c}-3.134^{* * *} \\
(0.605)\end{array}$ & $\begin{array}{c}1.077 \\
(1.347)\end{array}$ & $\begin{array}{c}-11.821 * * * \\
(1.647)\end{array}$ \\
\hline Wind Speed & $\begin{array}{l}-0.149 * * \\
(0.067)\end{array}$ & $\begin{array}{l}-0.120 * \\
(0.065)\end{array}$ & $\begin{array}{c}-0.005^{* *} \\
(0.002)\end{array}$ & $\begin{array}{c}1.945^{* * *} \\
(0.190)\end{array}$ & $\begin{array}{c}-0.645^{* * *} \\
(0.209)\end{array}$ & $\begin{array}{l}0.725 \text { * } \\
(0.387)\end{array}$ \\
\hline L.Wind Speed & $\begin{array}{c}-1.391^{* * *} \\
(0.106)\end{array}$ & $\begin{array}{c}-4.008^{* * *} \\
(0.113)\end{array}$ & $\begin{array}{c}-0.075^{* * *} \\
(0.004)\end{array}$ & $\begin{array}{c}0.584^{* * *} \\
(0.177)\end{array}$ & $\begin{array}{c}-5.363^{* * *} \\
(0.294)\end{array}$ & $\begin{array}{l}-0.563 \\
(0.645)\end{array}$ \\
\hline L2. Wind Speed & $\begin{array}{c}-1.239^{* * *} \\
(0.094)\end{array}$ & $\begin{array}{c}-3.363^{* * *} \\
(0.105)\end{array}$ & $\begin{array}{c}-0.084^{* * *} \\
(0.004)\end{array}$ & $\begin{array}{c}-2.013^{* * *} \\
(0.183)\end{array}$ & $\begin{array}{c}-7.452^{* * *} \\
(0.346)\end{array}$ & $\begin{array}{c}-6.733^{* * *} \\
(0.476)\end{array}$ \\
\hline L3. Wind Speed & $\begin{array}{c}-0.458^{* * *} \\
(0.056)\end{array}$ & $\begin{array}{c}-0.879 * * * \\
(0.069)\end{array}$ & $\begin{array}{c}-0.038^{* * *} \\
(0.003)\end{array}$ & $\begin{array}{c}-2.036^{* * *} \\
(0.173)\end{array}$ & $\begin{array}{c}-3.954^{* * *} \\
(0.295)\end{array}$ & $\begin{array}{c}-4.282^{* * *} \\
(0.428)\end{array}$ \\
\hline Temperature (Minimum) & $\begin{array}{c}0.129 * * * \\
(0.020)\end{array}$ & $\begin{array}{c}0.270^{* * *} \\
(0.021)\end{array}$ & $\begin{array}{c}-0.003^{* * *} \\
(0.001)\end{array}$ & $\begin{array}{c}2.105^{* * *} \\
(0.076)\end{array}$ & $\begin{array}{c}-0.242^{* * *} \\
(0.087)\end{array}$ & $\begin{array}{c}0.179 \\
(0.139)\end{array}$ \\
\hline Temperature (Highest) & $\begin{array}{c}-0.241^{* * *} \\
(0.027)\end{array}$ & $\begin{array}{c}-0.362^{* * *} \\
(0.031)\end{array}$ & $\begin{array}{c}-0.002 * \\
(0.001)\end{array}$ & $\begin{array}{c}-0.835^{* * *} \\
(0.081)\end{array}$ & $\begin{array}{l}0.314^{* *} \\
(0.151)\end{array}$ & $\begin{array}{l}0.649 * * \\
(0.304)\end{array}$ \\
\hline No-rain & $\begin{array}{c}-0.322 \text { *** } \\
(0.076)\end{array}$ & $\begin{array}{c}-0.735^{* * *} \\
(0.101)\end{array}$ & $\begin{array}{c}-0.029^{* * *} \\
(0.003)\end{array}$ & $\begin{array}{c}0.234 \\
(0.329)\end{array}$ & $\begin{array}{c}-0.735^{* *} \\
(0.351)\end{array}$ & $\begin{array}{c}0.711 \\
(0.662)\end{array}$ \\
\hline Constant & $\begin{array}{c}22.881^{* * *} \\
(1.059)\end{array}$ & $\begin{array}{c}54.813^{* * *} \\
(1.119)\end{array}$ & $\begin{array}{c}1.648^{* * *} \\
(0.040)\end{array}$ & $\begin{array}{c}57.874^{* * *} \\
(2.182)\end{array}$ & $\begin{array}{c}108.913^{* * *} \\
(3.177)\end{array}$ & $\begin{array}{c}135.890^{* * *} \\
(5.310)\end{array}$ \\
\hline Groups & 335 & 335 & 335 & 335 & 335 & 335 \\
\hline Sample & 72,281 & 72,281 & 72,281 & 72,281 & 72,281 & 72,281 \\
\hline adj R2 & 0.153 & 0.403 & 0.347 & 0.418 & 0.208 & 0.059 \\
\hline
\end{tabular}

Note: This table reports the regression results of the average impact of the COVID-19 lockdown on each pollutant for all cities in the sample. Standard errors reported in parentheses are clustered at the city level. ${ }^{* *} p<0.01,{ }^{* *} p<0.05,{ }^{*} p<0.1$.

First, the average impact on $\mathrm{SO}_{2}$ is positively significant at a 99.9 confidence interval. Surprisingly, its concentration during the COVID-19 pandemic increased by $1.68 \mu \mathrm{g} / \mathrm{m}^{3}$, or $14.71 \%$, compared to 2019 . This can be partly explained by the extension of the heating season in most northern cities. The statutory heating period ends around March 15 every year. However, in 2020, residents were required to stay at home. Therefore, most local governments postponed the end of collective heating to mid-April. The extended heating season and daily heating time increased $\mathrm{SO}_{2}$ emissions due to the massive combustion of coal $[47,48]$. 
Second, the concentration of $\mathrm{NO}_{2}$ in 2020 decreased by $5.11 \mu \mathrm{g} / \mathrm{m}^{3}$, or $19.24 \%$ compared to 2019. $\mathrm{NO}_{2}$ can be used to effectively measure traffic intensity, especially in urban areas [12,13]. $\mathrm{NO}_{2}$ has been identified as a typical pollutant associated with lockdown measures around the world $[9,49,50]$. Therefore, on average, vehicle kilometers traveled decreased by roughly $20 \%$ during the three months after the lockdown.

Third, CO concentration decreased by $0.105 \mathrm{mg} / \mathrm{m}^{3}$, or $30.88 \%$, compared to 2019 . Carbon monoxide is a by-product of the incomplete combustion of carbon-containing fuels, and on-road vehicles are a major source of $\mathrm{CO}$ in Chinese urban areas [51,52]. Besides, $\mathrm{CO}$ pollution mainly comes from small and medium passenger cars, while $\mathrm{NO}_{2}$ emissions mainly come from heavy-duty trucks in commercial vehicles. Therefore, as people remained sequestered in their residential areas, there were fewer passenger cars than heavy-duty trucks on the road, which led to a higher reduction of $\mathrm{CO}$ than $\mathrm{NO}_{2}$.

Fourth, the concentration of ground-level $\mathrm{O}_{3}$ increased by $3.881 \mu \mathrm{g} / \mathrm{m}^{3}$, or $3.74 \%$, compared to 2019. $\mathrm{O}_{3}$ is formed when nitrogen oxides react with a group of volatile organic compounds (VOCs) under the ultraviolet rays in the presence of sunlight [53]. The increase in the $\mathrm{O}_{3}$ level may be a consequence of three combined causes. First, the reduction of $\mathrm{NO}_{x}$ changes the ratio of VOCs to $\mathrm{NO}_{x}$ in VOC-controlled systems (which applies to most urban areas of China), increasing $\mathrm{O}_{3}$ concentration [54,55]. Second, $\mathrm{PM}_{2.5}$ reduces atmospheric visibility and significantly blocks ultraviolet rays from sunshine, which further leads to an increase in $\mathrm{O}_{3}$ [34]. Third, the reduction of $\mathrm{NO}_{\mathrm{x}}$ leads to the decrease of nitrogen oxide $\left(\mathrm{NO}, \mathrm{NO}_{\mathrm{x}}=\mathrm{NO}_{2}+\mathrm{NO}\right)$, which further reduces the $\mathrm{O}_{3}$ titration (consumption, $\mathrm{NO}+\mathrm{O}_{3}=\mathrm{NO}_{2}+\mathrm{O}_{2}$ ) $[54,56,57]$.

Finally, the concentration of $\mathrm{PM}_{2.5}$ decreased by $5.772 \mu \mathrm{g} / \mathrm{m}^{3}$, or $13.75 \%$, compared to 2019. $\mathrm{PM}_{2.5}$ is one of the pollutants that most affects air quality and is a secondary pollutant, which is formed in the atmosphere through the reaction, coagulation, or nucleation of precursor gases, especially $\mathrm{NO}_{2}$ and $\mathrm{SO}_{2}$ [58]. With the reduction of other pollutants, the $\mathrm{PM}_{2.5}$ level declined.

Our results can be compared with related studies done in other countries [59]. For example, Sharma, et al. [60] explored the impacts of COVID-19 related restrictions in 20 Indian cities and found that $\mathrm{PM}_{2.5}$ had the largest decrease, $43 \%$; by contrast, $\mathrm{CO}$ and $\mathrm{NO}_{2}$ only decreased by $10 \%$ and $18 \%$, respectively, and $\mathrm{SO}_{2}$ emissions were negligible. Since both China and India rely largely on coal as their primary energy resource, coal-fired boilers are the highest contributors to $\mathrm{SO}_{2}$ and $\mathrm{CO}$ emissions. Therefore, the comparison suggests that boilers were more affected by lockdown measures in China, while lockdown impacts on traffic-related emissions were similar in both countries. Tobías et al. [54] also found that $\mathrm{NO}_{2}$ emission markedly decreased in Barcelona (Spain), due to the strict restrictions in urban areas. Finally, nearly all studies found significant increases in $\mathrm{O}_{3}$ levels [55].

\section{Discussion: The Dynamic Patterns of the Lockdown Effects}

To study the dynamic pattern of how air quality was affected by the COVID-19-related lockdown, we estimated Equation (2) with 12 dummy variables, post 0 , post $1, \ldots$, post 11 , interacting with the treat dummy variable. The dummy variable post 0 is taken for the sample period $[0,7)$ after the event day, while post $1, \ldots$, post 11 are taken for the subsequent 11 weeks.

Figure 5 presents the pattern of the change in AQI. We also illustrate the change in the number of new infections (in its logarithmic form) on the second axis to detect the corresponding impact. In our quasi-DID design, the AQI decrease depicted in Figure 5 is the net impact, which is the air pollution level in 2020, minus that in 2019. Therefore, we observe patterns similar to the mechanism depicted in Figure 1. In the first two weeks of the lockdown, the AQI level is quite the same as it was in 2019, which confirms our assumption that the effects of the lockdown measures and the New Year holiday are comparable. In the third and fourth weeks, as the lockdown continued in most cities, the AQI level dropped by 20 points compared to 2019 . 


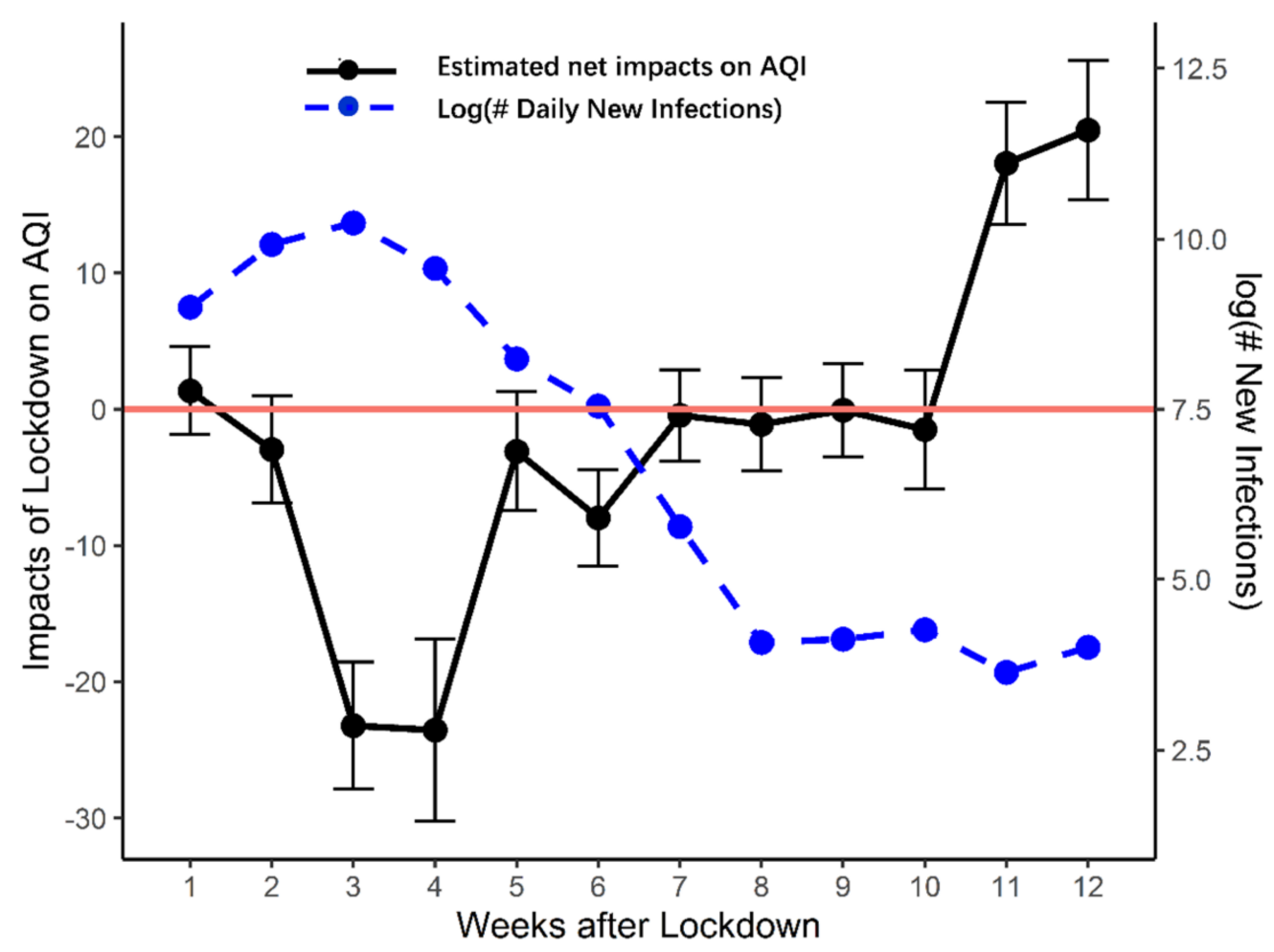

Figure 5. The dynamic air quality index (AQI) response. Note: This figure illustrates the dynamic air quality response. Changes in the daily AQI are the regression coefficients estimated from the DID regression on 12 weeks dummy variables (including post0, post $1, \ldots$, post11), interacting with a treat dummy variable, which is shown in Equation (2). The week dummy variable post 0 is taken for the sample period $[0,7)$ after the event day, while post $1, \ldots$, post11 are taken for the subsequent 11 weeks after the event day. Treat is equal to 1 for observations in 2020, and 0 for observations in 2019. The event day is January 23 for 2020 (the date when the Wuhan lockdown was implemented), while the event day for 2019 is February 5, one day before 2019 Chinese New Year's Eve. The error bar indicates a 95\% confidence interval. The incremental \# of weekly novel COVID-19 cases is the total number of COVID-19 cases confirmed during the event week.

After week 4, the AQI climbed steeply back to its normal level over three weeks. As the number of daily new infections dropped in early March, most cities gradually moved closer to normality; hence the treatment effect fades away. On average, the AQI steadily returned to its normal level about seven weeks after the end of the lockdown of Wuhan city. The temporary improvements in air pollution from the lockdown only lasted for one month for the average city in mainland China.

The turning point comes just one month after the event day. Although most analysts thought that local governors were reluctant to reopen cities due to fear of the epidemic resurging, our analysis shows that the AQI increased immediately after novel infections dropped, which is a quick response. The AQI plateaued for four consecutive weeks after week 7. During this month, the AQI gradually returned to the same level that it was in the same period in 2019 after economic activity resumed. Finally, the AQI increased sharply in the last two weeks. We find strong rebound effects after April 8, immediately after the epicenter lifted its lockdown measures. It suggests that pollution-related industrial and business activities bounced back after 2019 as the government called for a restart of the economy.

Figure 6 depicts the association between the AQI and daily new infections. The straight line in the scatterplot shows that the more daily new infections, the better the air quality. When the number of daily new infections is highest, human activities are strictly monitored, and people are required to stay at home. As the number of daily new infections gradually decreases, control measures also gradually relax. Simultaneously, people start to resume work, and companies begin production activities, leading to a decline in air quality. 


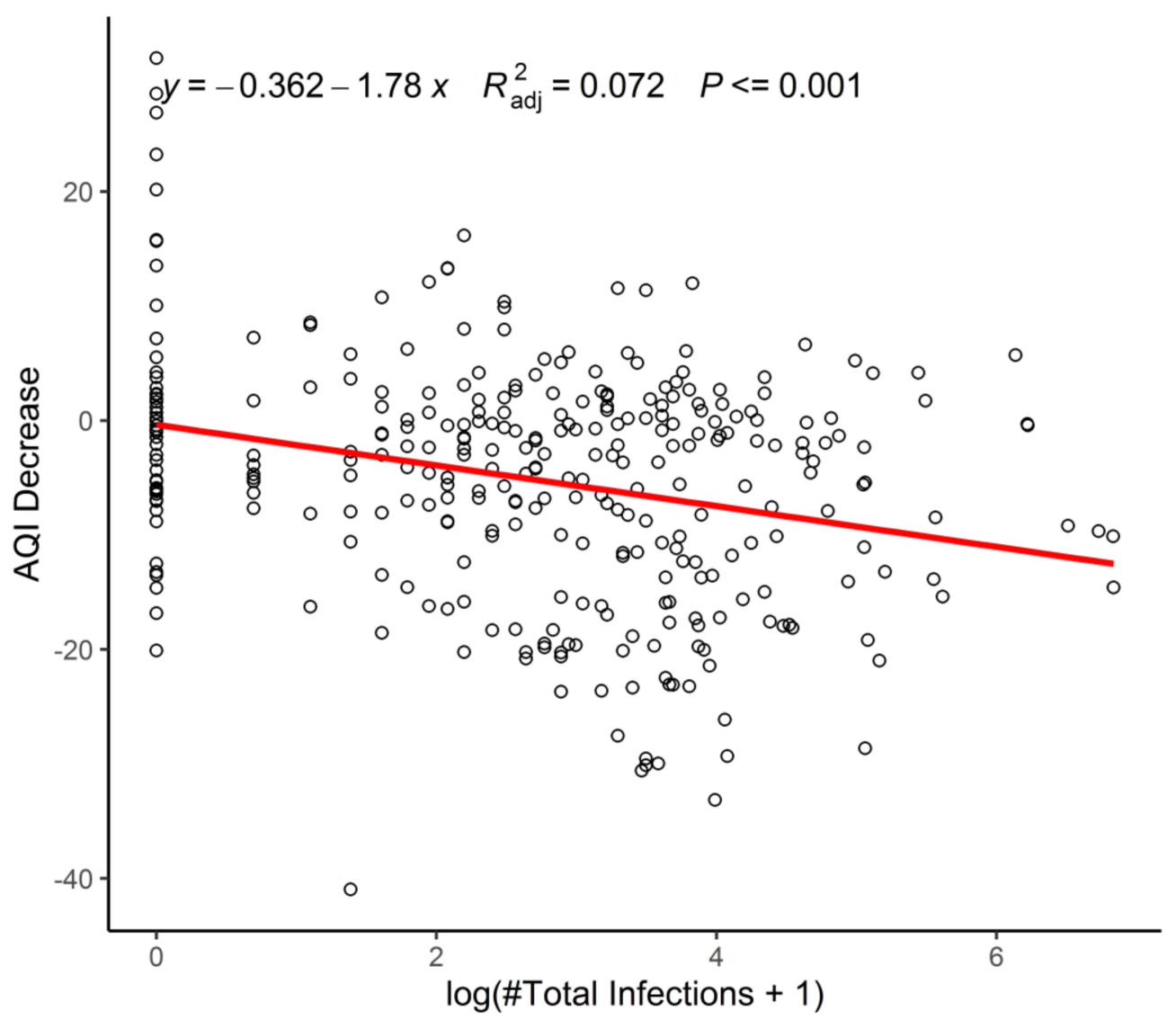

Figure 6. The association between the air quality index (AQI) and the daily new infections. Note: This figure shows the impact of the daily new COVID-19 cases on the AQI across cities. It displays the simple scatterplot between the AQI and the total number of COVID-19 cases as of 22 April 2020. We also included the fitted line in the scatterplot.

To summarize, our estimation suggests that the lockdown's impact on the AQI persisted for nearly four weeks, from January 23 to late February. The AQI then returned to its normal level and seesawed up and down for more than one month. Lastly, as daily new infections went down and mass quarantine measures were relaxed and then eventually removed, and air pollution increased significantly.

Figure 7 shows the dynamic change of each major air pollutant's concentration. Although their u-shape patterns are similar to that of the AQI, we find subtle differences among pollutants, which are worth exploring. However, $\mathrm{SO}_{2}$ exhibits a unique pattern during the epidemic period. This is because most northern cities expanded their heating season to mid-April, which increased $\mathrm{SO}_{2}$ emissions.

Among the six pollutant criteria, the changes in $\mathrm{NO}_{2}$ levels are the most typical. In urban areas, vehicles are the major source of $\mathrm{NO}_{2}$ emission. Therefore, $\mathrm{NO}_{2}$ concentrations are an effective way to measure traffic. As shown in Figure 7, in the first week of lockdown, $\mathrm{NO}_{2}$ concentration is similar to that in 2019. However, soon after, there is a steep decline in $\mathrm{NO}_{2}$ levels, which suggests that residents were still sequestered in their houses. It only started to increase after week 4.

The changing trend of $\mathrm{PM}_{2.5}$ mirrors that of $\mathrm{NO}_{2}$. In the first two weeks of lockdown, the $\mathrm{PM}_{2.5}$ level was higher than that of the same period in 2019, and then it plummeted. It started to bounce back after the fourth week. However, it remained lower than the $\mathrm{PM}_{2.5}$ levels of the same period in 2019. In the eleventh week, it returned to a level higher than that in 2019. The overall changing trend of $\mathrm{PM}_{10}$ also declined first and then increased. For $\mathrm{PM}_{10}$, its level in the first week during the lockdown was lower than that of the same period in 2019, while in the second week, it rose to the same level as in 2019, then began to decline. It started to bounce back after the fourth week. However, there was a decline from 
the fifth to the sixth week. Again, it continued to rise, and after eight weeks, it reached a level that was higher than that of the same period in 2019. These patterns can be explained as follows. The main sources of $\mathrm{PM}_{2.5}$ are the residues of power generation, industrial production, vehicle exhaust emissions, and coal-burning [60]. Although power generation did not decrease, and coal-burning increased, vehicle exhaust emissions and industrial production greatly reduced, thus resulting in a reduction of $\mathrm{PM}_{2.5}$ during the lockdown. However, most of the time, the $\mathrm{PM}_{10}$ level was higher than or equal to that of the same period in 2019, which is most likely due to increased coal-burning during the lockdown. Meanwhile, the reduction of certain pollutants in the atmosphere changed the composition ratio of substances, allowing compounds to interact to form more fine particles [6].
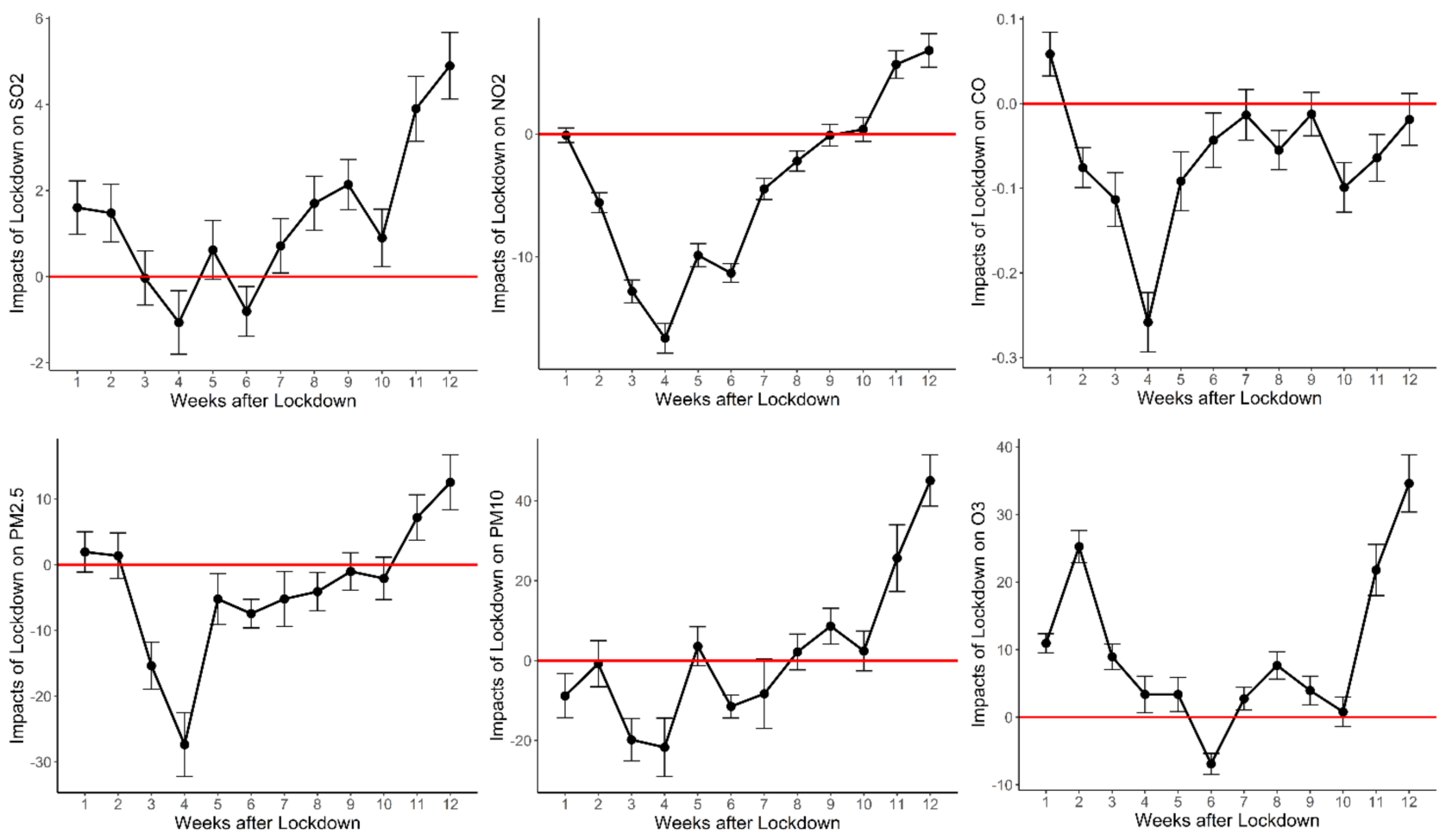

Figure 7. Concentration changes of air pollutants over time: by categories. Note: This figure presents the dynamic pollutant concentration responses by categories. Changes in daily average concentration are the regression coefficients estimated from the DID regression on 12 week dummy variables (including post0, post $1, \ldots$, post11), interacting with a treat dummy variable, which is shown in Equation (2). The week dummy variable post0 is taken for the sample period $[0,7)$ after the event day, while post $1, \ldots$, post 11 are taken for the subsequent 11 weeks after the event day. Treat is equal to 1 for observations in 2020, and 0 for observations in 2019. The event day is January 23 for 2020 (the date when the Wuhan lockdown was implemented), while the event day for 2019 is February 5, one day before the 2019 Chinese New Year's Eve. The error bar indicates a $95 \%$ confidence interval.

Regarding $\mathrm{O}_{3}$, its level rose from the first to the second week and then plummeted. However, it was not until the sixth week that for the first time, its level fell below that of the same period in 2019. It then started to bounce back, and it remained higher than that of the same period in 2019. The increase of $\mathrm{O}_{3}$ can be explained by three reasons. First, the decrease in $\mathrm{NO}_{x}$ led to the change in its ratio to VOCs, which in turn led to an increase in $\mathrm{O}_{3}$ concentration $[55,61]$. Second, the lower $\mathrm{PM}_{2.5}$ concentrations reduced the scattering and absorption of sunlight, which increased UV radiation and led to a higher $\mathrm{O}_{3}$ concentration [34]. Third, the decreased $\mathrm{NO}_{\mathrm{x}}$ reduced the consumption of $\mathrm{O}_{3}$ $\left(\mathrm{NO}+\mathrm{O}_{3}=\mathrm{NO}_{2}+\mathrm{O}_{2}\right)$ in urban areas, thus leading to higher $\mathrm{O}_{3}$ concentrations [50].

To sum up, the heterogeneous dynamic patterns of different pollutants are related to changes in substantive human activities. Significant rebound effects were detected for 
almost all pollutants after the lockdown was lifted, which triggers concerns about the long-term impacts of the COVID-19 lockdown on air pollution.

Although the above results indicate a quick rebound on average, there is much heterogeneity among regions. Figure 8 depicts a heat map of urban $\mathrm{NO}_{2}$ concentration nationwide, which shows the spatial-temporal fluctuation of $\mathrm{NO}_{2}$ concentration. In Panel A, $\mathrm{NO}_{2}$ concentration three weeks pre-lockdown can be considered as the usual pattern. Four pollution hotspots are clear and include the Capital Region, the Yangtze River Delta, the Pearl River Delta, and the Sichuan Basin. Compared with Panel A, Panel B indicates that the lockdown reduced $\mathrm{NO}_{2}$ concentrations drastically and uniformly from the first to the fourth week nationwide. However, as shown in Panel E, air pollution rebounded much faster in the Yangtze River Delta and the Pearl River Delta and was much slower to increase in other hotspots, namely the Sichuan Basin and the Capital Region. The stark differences in rebound suggest regional differences in industrial structures and other institutional factors. For example, the export sectors in the southern regions are more vital, especially those manufacturing personal protective equipment, which was affected by the surge of infections in other countries.

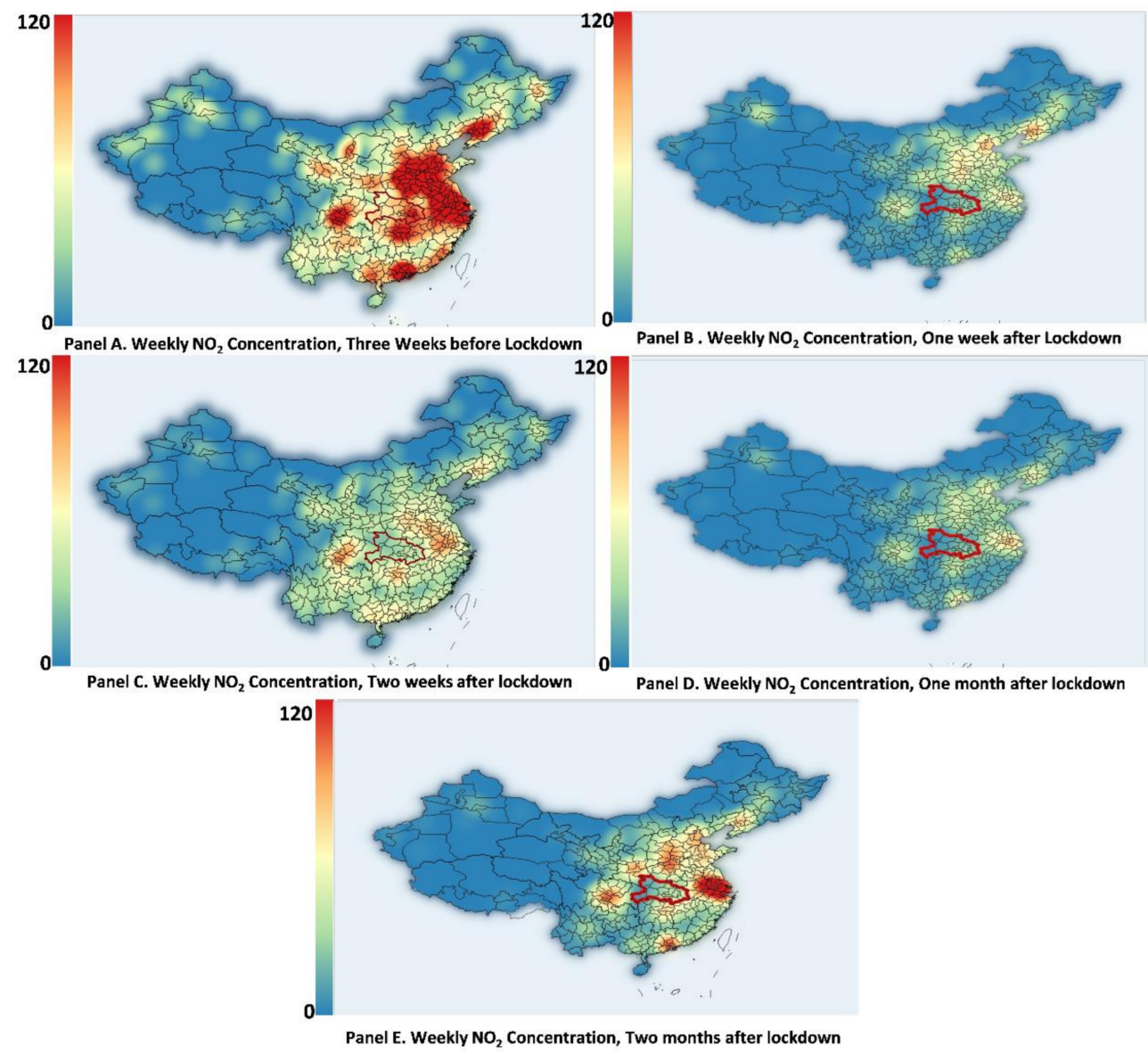

Figure 8. Heat maps of weekly $\mathrm{NO}_{2}$ concentration across China during the COVID-19-related lockdown period.Notes: This figure presents the weekly average $\mathrm{NO}_{2}$ concentration across China before and after the COVID-19 lockdown. The epicenter, Hubei Province is outlined in a red circle. The weekly average is adopted to curb the stochastic influence of weather conditions.

\section{Conclusions}

In this study, we conducted a quasi-DID analysis of the impacts of COVID-19-related lockdown measures on air quality in China. Our study covers 367 prefectural- and countylevel cities during the epidemic period from the beginning of the lockdown until two weeks after its lifting in Wuhan. The results suggest the following. 
First, on average, the AQI decreased by about $7 \%$. Although our results indicate immense improvements, air quality levels were still over the threshold set by the WHO and Chinese standards. Second, we detected significant heterogeneous impacts on different pollutants. $\mathrm{CO}$ had the biggest drop, about $30 \%$, and $\mathrm{NO}_{2}$ had the second-largest drop, about $20 \%$. In contrast, $\mathrm{O}_{3}$ increased by $3.74 \%$. We attribute these differences to the lockdown's heterogeneous impacts on different anthropogenic activities. Concentrations of $\mathrm{CO}$ and $\mathrm{NO}_{2}$ were sharply reduced from traffic restriction measures meant to contain the viral transmission, while $\mathrm{O}_{3}$ increased because the reduction of $\mathrm{PM}_{2.5}$ and $\mathrm{PM}_{10}$ in the troposphere increased the UV radiation, which in turn increased photochemical reaction intensity. Third, although the AQI reduced steeply after the lockdown, it increased immediately after the number of novel infections dropped, which is a quick response. Finally, we also detected preliminary cues of the rebound effect, immediately after the lifting of lockdown measures in Wuhan.

Our study also sheds some light on the effectiveness of the quick-response measures put into place after the declaration of an environmental emergency, especially when urban air quality reaches the red alert level, which, according to WHO standards, is extremely toxic for humans. Quick and temporary restrictive measures, including activity suspension of heavy-polluting plants and traffic restrictions based on the last digit of license plate numbers, can be effective at lowering $\mathrm{NO}_{2}, \mathrm{SO}_{2}$, and $\mathrm{PM}_{2.5}$ concentrations. However, policymakers should be cautious about increases in $\mathrm{O}_{3}$ concentrations.

One limitation of our study is that as the epidemic is fading away in China, its long-term impacts are still not clear. On the one hand, some suggest that environmental degradation due to the extreme, massive economic stimulus will occur. On the other hand, COVID-19 is more infectious compared to severe acute respiratory syndrome (SARS), which emerged in 2002 in China. Lifestyles may change permanently in a more sustainable direction. For example, virtual meetings are now held more frequently, and white-collar workers prefer working from home. Moreover, instead of simply turning to the old playbook of investment stimulus, the government has launched a new infrastructure initiative, which mainly incorporates fifth-generation networks, industrial internet, intercity transit systems, vehicle charging stations, data centers, and several other projects. These policies would lead to more sustainable growth. Therefore, instead of focusing on the short-term environmental effects related to the lockdown, it would be worthwhile to expand our research to explore the potential permanent environmental impacts of the COVID-19 lockdown.

Author Contributions: T.Z.: Conceptualization, methodology, data collection, visualization, and writing the original draft preparation; M.T.: Conceptualization, writing, reviewing, and editing. All authors have read and agreed to the published version of the manuscript.

Funding: This research was funded by the Major Project on Humanities and Social Sciences of the Shanghai Municipal Education Commission Research and Innovation Program, 2017-01-07-00-02E00008, as well as the National Natural Science Foundation of China, 72073045.

Institutional Review Board Statement: Not applicable.

Informed Consent Statement: Not applicable.

Data Availability Statement: The data presented in this study are available on request from the corresponding author. The urban air quality data can also be downloaded directly from website of China National Urban Air Quality Real-time Publishing Platform (http:/ /106.37.208.233:20035/) and the prefectural COVID infection data can be collected from the https://github.com/GuangchuangYu/ nCov2019.

Acknowledgments: Thanks to the audience for their seminal comments at the second International Conference on "China Development Theory". We also thank the anonymous reviewers for their helpful and valuable comments and suggestions to improve the quality of the study.

Conflicts of Interest: The authors declare no conflict of interest concerning the publication of this study. 


\section{References}

1. Zhu, N.; Zhang, D.; Wang, W.; Li, X.; Yang, B.; Song, J.; Zhao, X.; Huang, B.; Shi, W.; Lu, R.; et al. A novel coronavirus from patients with pneumonia in China, 2019. N. Engl. J. Med. 2020, 382, 727-733. [CrossRef] [PubMed]

2. Lau, H.; Khosrawipour, V.; Kocbach, P.; Mikolajczyk, A.; Schubert, J.; Bania, J.; Khosrawipour, T. The positive impact of lockdown in Wuhan on containing the COVID-19 outbreak in China. J. Travel Med. 2020, 27, taaa037. [CrossRef]

3. He, G.; Pan, Y.; Tanaka, T. The short-term impacts of COVID-19 lockdown on urban air pollution in China. Nat. Sustain. 2020, 3 , 1005-1011. [CrossRef]

4. Sun, G.-Q.; Wang, S.-F.; Li, M.-T.; Li, L.; Zhang, J.; Zhang, W.; Jin, Z.; Feng, G.-L. Transmission dynamics of COVID-19 in Wuhan, China: Effects of lockdown and medical resources. Nonlinear Dyn. 2020, 101, 1981-1993. [CrossRef]

5. Ji, T.; Chen, H.-L.; Xu, J.; Wu, L.-N.; Li, J.-J.; Chen, K.; Qin, G. Lockdown contained the spread of 2019 novel coronavirus disease in Huangshi city, China: Early epidemiological findings. Clin. Infect. Dis. 2020, 71, 1454-1460. [CrossRef] [PubMed]

6. Muhammad, S.; Long, X.; Salman, M. COVID-19 pandemic and environmental pollution: A blessing in disguise? Sci. Total Environ. 2020, 728, 138820. [CrossRef] [PubMed]

7. Elavarasan, R.M.; Shafiullah, G.; Raju, K.; Mudgal, V.; Arif, M.T.; Jamal, T.; Subramanian, S.; Balaguru, V.S.; Reddy, K.; Subramaniam, U. COVID-19: Impact analysis and recommendations for power sector operation. Appl. Energ. 2020, $279,115739$. [CrossRef] [PubMed]

8. Wang, Q.; Lu, M.; Bai, Z.; Wang, K. Coronavirus pandemic reduced China's CO2 emissions in short-term, while stimulus packages may lead to emissions growth in medium-and long-term. Appl. Energ. 2020, 278, 115735. [CrossRef]

9. Dutheil, F.; Baker, J.S.; Navel, V. COVID-19 as a factor influencing air pollution? Environ. Pollut. 2020, 263, 114466. [CrossRef]

10. He, C.; Yang, L.; Cai, B.; Ruan, Q.; Hong, S.; Wang, Z. Impacts of the COVID-19 event on the NOx emissions of key polluting enterprises in China. Appl. Energ. 2020, 281, 116042. [CrossRef]

11. Verma, S.; Gustafsson, A. Investigating the emerging COVID-19 research trends in the field of business and management: A bibliometric analysis approach. J. Bus. Res. 2020, 118, 253-261. [CrossRef] [PubMed]

12. He, M.Z.; Kinney, P.L.; Li, T.; Chen, C.; Sun, Q.; Ban, J.; Wang, J.; Liu, S.; Goldsmith, J.; Kioumourtzoglou, M.-A. Short-and intermediateterm exposure to $\mathrm{NO}_{2}$ and mortality: A multi-county analysis in China. Environ. Pollut. 2020, 261, 114165. [CrossRef] [PubMed]

13. He, L.; Zhang, S.; Hu, J.; Li, Z.; Zheng, X.; Cao, Y.; Xu, G.; Yan, M.; Wu, Y. On-road emission measurements of reactive nitrogen compounds from heavy-duty diesel trucks in China. Environ. Pollut. 2020, 262, 114280. [CrossRef] [PubMed]

14. Hao, Y.; Xie, S. Optimal redistribution of an urban air quality monitoring network using atmospheric dispersion model and genetic algorithm. Atmos. Environ. 2018, 177, 222-233. [CrossRef]

15. He, J.; Gong, S.; Yu, Y.; Yu, L.; Wu, L.; Mao, H.; Song, C.; Zhao, S.; Liu, H.; Li, X. Air pollution characteristics and their relation to meteorological conditions during 2014-2015 in major Chinese cities. Environ. Pollut. 2017, 223, 484-496. [CrossRef]

16. Chan, L.; Kwok, W. Roadside suspended particulates at heavily trafficked urban sites of Hong Kong-Seasonal variation and dependence on meteorological conditions. Atmos. Environ. 2001, 35, 3177-3182. [CrossRef]

17. Zhao, D.; Chen, H.; Li, X.; Ma, X. Air pollution and its influential factors in China's hot spots. J. Clean. Prod. 2018, 185, 619-627. [CrossRef]

18. Jayamurugan, R.; Kumaravel, B.; Palanivelraja, S.; Chockalingam, M. Influence of temperature, relative humidity and seasonal variability on ambient air quality in a coastal urban area. Int. J. Atmos. Sci. 2013, 2013, 264046. [CrossRef]

19. Tu, J.; Wang, H.; Zhang, Z.; Jin, X.; Li, W. Trends in chemical composition of precipitation in Nanjing, China, during 1992-2003. Atmos. Res. 2005, 73, 283-298. [CrossRef]

20. Chen, W.; Tang, H.; Zhao, H. Diurnal, weekly and monthly spatial variations of air pollutants and air quality of Beijing. Atmos. Environ. 2015, 119, 21-34. [CrossRef]

21. Chiquetto, J.B.; Alvim, D.S.; Rozante, J.R.; Faria, M.; Rozante, V.; Gobo, J.P.A. Impact of a truck Driver's strike on air pollution levels in São Paulo. Atmos. Environ. 2021, 246, 118072. [CrossRef]

22. Li, Y.; Wang, W.; Kan, H.; Xu, X.; Chen, B. Air quality and outpatient visits for asthma in adults during the 2008 Summer Olympic Games in Beijing. Sci. Total Environ. 2010, 408, 1226-1227. [CrossRef]

23. Feng, J.; Sun, P.; Hu, X.; Zhao, W.; Wu, M.; Fu, J. The chemical composition and sources of PM2. 5 during the 2009 Chinese New Year's holiday in Shanghai. Atmos. Res. 2012, 118, 435-444. [CrossRef]

24. Tan, P.-H.; Chou, C.; Liang, J.-Y.; Chou, C.C.-K.; Shiu, C.-J. Air pollution "holiday effect" resulting from the Chinese New Year. Atmos. Environ. 2009, 43, 2114-2124. [CrossRef]

25. Tan, P.-H.; Chou, C.; Chou, C.C.-K. Impact of urbanization on the air pollution "holiday effect" in Taiwan. Atmos. Environ. 2013, 70, 361-375. [CrossRef]

26. Hua, J.; Zhang, Y.; de Foy, B.; Mei, X.; Shang, J.; Feng, C. Competing PM2. 5 and NO2 holiday effects in the Beijing area vary locally due to differences in residential coal burning and traffic patterns. Sci. Total Environ. 2020, 750, 141575. [CrossRef]

27. Wilder-Smith, A.; Freedman, D.O. Isolation, quarantine, social distancing and community containment: Pivotal role for old-style public health measures in the novel coronavirus (2019-nCoV) outbreak. J. Travel Med. 2020, 27, taaa020. [CrossRef] [PubMed]

28. Pepe, E.; Bajardi, P.; Gauvin, L.; Privitera, F.; Lake, B.; Cattuto, C.; Tizzoni, M. COVID-19 outbreak response: A dataset to assess mobility changes in Italy following national lockdown. Sci. Data 2020, 7, 230. [CrossRef] 
29. Li, L.; Li, Q.; Huang, L.; Wang, Q.; Zhu, A.; Xu, J.; Liu, Z.; Li, H.; Shi, L.; Li, R. Air quality changes during the COVID-19 lockdown over the Yangtze River Delta Region: An insight into the impact of human activity pattern changes on air pollution variation. Sci. Total Environ. 2020, 732, 139282. [CrossRef] [PubMed]

30. Guo, F.; Shi, Q. Official turnover, collusion deterrent and temporary improvement of air quality. Econ. Res. J. 2017, 52, 155-168. (In Chinese)

31. Shi, Q.; Guo, F.; Chen, S. "Political Blue Sky" in fog and haze governance: Evidence from the local annual "Two Sessions" in China. Chin. Ind. Econ. J. 2016, 40-56. (In Chinese) [CrossRef]

32. World Health Organization. Air Quality Guidelines: Global Update 2005: Particulate Matter, Ozone, Nitrogen Dioxide, and Sulfur Dioxide; World Health Organization: Geneva, Switzerland, 2006.

33. Wooldridge, J.M. Econometric Analysis of Cross Section and Panel Data; MIT Press: Cambridge, MA, USA, 2010.

34. Wang, P.; Guo, H.; Hu, J.; Kota, S.H.; Ying, Q.; Zhang, H. Responses of PM2.5 and $\mathrm{O}_{3}$ concentrations to changes of meteorology and emissions in China. Sci. Total Environ. 2019, 662, 297-306. [CrossRef] [PubMed]

35. Mahmud, A.; Hixson, M.; Kleeman, M. Quantifying population exposure to airborne particulate matter during extreme events in California due to climate change. Atmos. Chem. Phys. 2012, 12, 7453. [CrossRef]

36. Megaritis, A.; Fountoukis, C.; Charalampidis, P.; Van Der Gon, H.D.; Pilinis, C.; Pandis, S. Linking climate and air quality over Europe: Effects of meteorology on PM2.5 concentrations. Atmos. Chem. Phys. 2014, 14, 10283-10298. [CrossRef]

37. Kota, S.H.; Guo, H.; Myllyvirta, L.; Hu, J.; Sahu, S.K.; Garaga, R.; Ying, Q.; Gao, A.; Dahiya, S.; Wang, Y. Year-long simulation of gaseous and particulate air pollutants in India. Atmos. Environ. 2018, 180, 244-255. [CrossRef]

38. Wang, P.; Chen, K.; Zhu, S.; Wang, P.; Zhang, H. Severe air pollution events not avoided by reduced anthropogenic activities during COVID-19 outbreak. Resour. Conserv. Recy. 2020, 158, 104814. [CrossRef] [PubMed]

39. De Leon, S.F.; Thurston, G.D.; Ito, K. Contribution of respiratory disease to nonrespiratory mortality associations with air pollution. Am. J. Respir. Crit. Care Med. 2003, 167, 1117-1123. [CrossRef] [PubMed]

40. Ferkol, T.; Schraufnagel, D. The global burden of respiratory disease. Ann. Am. Thorac. Soc. 2014, 11, 404-406. [CrossRef]

41. Lee, B.-J.; Kim, B.; Lee, K. Air pollution exposure and cardiovascular disease. Toxicol. Res. 2014, 30, 71-75. [CrossRef] [PubMed]

42. Franchini, M.; Mannucci, P.M. Air pollution and cardiovascular disease. Thromb. Res. 2012, 129, 230-234. [CrossRef] [PubMed]

43. Schwartz, J. The distributed lag between air pollution and daily deaths. Epidemiology 2000, 11, 320-326. [CrossRef] [PubMed]

44. Landrigan, P.J. Air pollution and health. Lancet Public Health 2017, 2, e4-e5. [CrossRef]

45. Clancy, L.; Goodman, P.; Sinclair, H.; Dockery, D.W. Effect of air-pollution control on death rates in Dublin, Ireland: An intervention study. Lancet 2002, 360, 1210-1214. [CrossRef]

46. Rohde, R.A.; Muller, R.A. Air pollution in China: Mapping of concentrations and sources. PLoS ONE 2015, 10, e0135749. [CrossRef]

47. Ebenstein, A.; Fan, M.; Greenstone, M.; He, G.; Zhou, M. New evidence on the impact of sustained exposure to air pollution on life expectancy from China's Huai River Policy. Proc. Natl. Acad. Sci. USA 2017, 114, 10384-10389. [CrossRef] [PubMed]

48. Almond, D.; Chen, Y.; Greenstone, M.; Li, H. Winter heating or clean air? Unintended impacts of China's Huai river policy. Am. Econ. Rev. 2009, 99, 184-190. [CrossRef]

49. Fattorini, D.; Regoli, F. Role of the chronic air pollution levels in the Covid-19 outbreak risk in Italy. Environ. Pollut. 2020, 264, 114732. [CrossRef]

50. Mahato, S.; Pal, S.; Ghosh, K.G. Effect of lockdown amid COVID-19 pandemic on air quality of the megacity Delhi, India. Sci. Total Environ. 2020, 730, 139086. [CrossRef] [PubMed]

51. Westerdahl, D.; Wang, X.; Pan, X.; Zhang, K.M. Characterization of on-road vehicle emission factors and microenvironmental air quality in Beijing, China. Atmos. Environ. 2009, 43, 697-705. [CrossRef]

52. Ding, A.; Wang, T.; Fu, C. Transport characteristics and origins of carbon monoxide and ozone in Hong Kong, South China. J. Geophys. Res. Atmos. 2013, 118, 9475-9488. [CrossRef]

53. Shao, M.; Zhang, Y.; Zeng, L.; Tang, X.; Zhang, J.; Zhong, L.; Wang, B. Ground-level ozone in the Pearl River Delta and the roles of VOC and NOx in its production. J. Environ. Manag. 2009, 90, 512-518. [CrossRef] [PubMed]

54. Tobías, A.; Carnerero, C.; Reche, C.; Massagué, J.; Via, M.; Minguillón, M.C.; Alastuey, A.; Querol, X. Changes in air quality during the lockdown in Barcelona (Spain) one month into the SARS-CoV-2 epidemic. Sci. Total Environ. 2020, 726, 138540. [CrossRef] [PubMed]

55. Siciliano, B.; Dantas, G.; da Silva, C.M.; Arbilla, G. Increased ozone levels during the COVID-19 lockdown: Analysis for the city of Rio de Janeiro, Brazil. Sci. Total Environ. 2020, 737, 139765. [CrossRef] [PubMed]

56. Dantas, G.; Siciliano, B.; França, B.B.; da Silva, C.M.; Arbilla, G. The impact of COVID-19 partial lockdown on the air quality of the city of Rio de Janeiro, Brazil. Sci. Total Environ. 2020, 729, 139085. [CrossRef]

57. Nakada, L.Y.K.; Urban, R.C. COVID-19 pandemic: Impacts on the air quality during the partial lockdown in São Paulo state, Brazil. Sci. Total Environ. 2020, 730, 139087. [CrossRef]

58. Hodan, W.M.; Barnard, W.R. Evaluating the Contribution of PM2.5 Precursor Gases and Re-Entrained Road Emissions to Mobile Source PM2.5 Particulate Matter Emissions; MACTEC: Durham, NC, USA, 2004.

59. Cadotte, M. Early evidence that COVID-19 government policies reduce urban air pollution. EarthArXiv 2020. [CrossRef]

60. Sharma, S.; Zhang, M.; Gao, J.; Zhang, H.; Kota, S.H. Effect of restricted emissions during COVID-19 on air quality in India. Sci. Total Environ. 2020, 728, 138878. [CrossRef] [PubMed]

61. Jiménez, P.; Baldasano, J.M. Ozone response to precursor controls in very complex terrains: Use of photochemical indicators to assess O3-NOx-VOC sensitivity in the northeastern Iberian Peninsula. J. Geophys. Res. Atmos. 2004, 109, D20309. [CrossRef] 